\title{
La "trampa política de la pobreza": Bolivia 1999-2009*
}

\author{
Paul Mosley \\ Departamento de Economía \\ Universidad de Sheffield
}

\begin{abstract}
Resumen
El presente artículo analiza la reciente ola de inestabilidad política en Bolivia, en el contexto de un modelo de "la trampa de pobreza". Dicho modelo sugiere cuáles son los elementos del sistema político del país, así como su estructura económica, que pueden ser instrumentales en la perpetuación de un estado de pobreza. En la reciente fase de inestabilidad, en Bolivia, los costes del ajuste han sido muy graves, con más de un centenar de muertos entre 1999 y 2005 como consecuencia de las manifestaciones en contra de aspectos de la globalización y el proceso de ajuste. En un aparente retorno a un estado de inestabilidad política crónica, otros países afectados por una crisis global han sufrido menos. ¿Esto es debido a que utilizaron los instrumentos de ajuste más efectivos o por otras razones? En particular, ¿cómo el impacto en la pobreza se ajusta en esta historia: un patrón de ajuste "más efectivo" habría tenido un mayor efecto en la reducción de la pobreza?
\end{abstract}

Palabras clave: Bolivia, trampa de la pobreza, inestabilidad política.

Classificación JEL: D72, D74, O23.

\begin{abstract}
We analyse the recent wave of political instability in Bolivia in the context of a 'poverty trap' model which suggests that elements in a country's political system, as well as its economic structure, may be instrumental in perpetuating a state of poverty. In Bolivia the costs of adjustment in the recent phase have been very severe, with well over a hundred killed between 1999 and 2007 as a direct consequence of demonstrations against aspects of the globalisation and adjustment process, and an appearance of a return to a state of chronic political instability; other countries affected by the global crisis have suffered less severely. We ask: is this because they used the available instruments of adjustment more effectively, or for other reasons? In particular, how does poverty impact fit into the story: would a 'more effective' pattern of adjustment have been more propoor?
\end{abstract}

Keywords: Bolivia, poverty trap, political instability.

JEL Classification: D72, D74, O23.

* Agradecimientos especiales a: Irina Aliaga, Jose Antonio Alonso, Ramiro Alvarez, Fernando Landa, Cayetano Llobet, Reynaldo Marconi, Walter Nunez, Rodney Pereira, Pia Riggirozzi, Fernando Romero y los miembros del Departamento de Staff de Gobierno de la Universidad de Essex, Seminario del 21 de Febrero de 2006. La traducción del artículo ha sido realizada por el autor, los errores u omisiones son responsabilidad única del autor. Agradecimientos al apoyo de ESRC con las concesiones RES-000-22-1168 y RES-156-25-00016. 


\section{Introducción: la violencia política y las variedades de la experiencia de estabilización}

El 12 y 13 de Octubre de 2003, más de sesenta personas ${ }^{1}$ murieron en una confrontación entre manifestantes civiles y las fuerzas armadas, en la ciudad de El Alto, Bolivia. El incidente marcó el clímax de una serie de disturbios, que han continuado a través del presente año, señalando a Bolivia como uno de los países más gravemente afectados en términos humanos tras la ola de crisis financieras y monetarias que golpearon a los países en desarrollo en 1997 y que tuvieron su origen inicial en el Este de Asia. La variedad de experiencias en conflictos relacionados con la respuesta al ajuste económico, en países en desarrollo, desde el año 1997 se recoge en el Cuadro 1.

\section{CUADRO 1}

PAÍSES AFECTADOS POR LA CRISIS GLOBAL (1997-2005): LAS RESPUESTAS POLÍTICAS Y SUS CONSECUENCIAS

\begin{tabular}{|l|c|c|c|}
\hline \multicolumn{1}{|c|}{ País } & $\begin{array}{c}\text { Año de ingreso } \\
\text { en crisis }\end{array}$ & $\begin{array}{c}\text { Duración de la crisis } \\
\text { (años de crecimiento } \\
\text { negativo del PIB per capita, } \\
\text { siguiendo el efecto } \\
\text { de la crisis) }\end{array}$ & $\begin{array}{c}\text { Muertes } \\
\text { y violencia política } \\
\text { asociada a las crisis }\end{array}$ \\
\hline Tailandia & 1997 & 1 & 0 \\
\hline Corea del Sur & 1997 & 2 & 2 \\
\hline Indonesia & 1997 & 2 & $>1000$ \\
\hline Malasia & 1998 & 1 & 0 \\
\hline Rusia & 1998 & 3 & $25(\mathrm{e})$ \\
\hline Turquía & 1998 & 2 & Sin datos \\
\hline Brasil & 1999 & 1 & 12 \\
\hline Argentina & 2000 & 3 & 140 \\
\hline Bolivia & 1999 & 6 & \\
\hline
\end{tabular}

Fuentes: Banco Mundial, CD de Indicadores de Desarrollo Mundiales, Banco Mundial (Washington DC, 2005). (e) significa estimado. Para las muertes asociadas con violencia política, ver Mosley et al (2009), ch. 4.

A partir de la tabla presentada, queda claro que la interacción entre los costes sociales de la crisis y las consecuencias políticas fueron en algunos casos de corto pla-

\footnotetext{
${ }^{1}$ Algunos registros dan cuentan de más de 80 muertes, por ejemplo Suárez (2003).
} 
zo y con tendencia a autocorregirse (por ejemplo, en Corea del Sur, Malasia y Tailandia), pero en otros casos fue de largo plazo y con tendencia a autoreforzarse (por ejemplo, en Indonesia, Turquía, Argentina y Bolivia). En este artículo se busca comprender porqué ocurren estas diferencias en el patrón de respuestas, con referencia particular al caso de Bolivia, donde la crisis reciente ha restablecido un patrón ancestral de inestabilidad, después de haberse salvado aparentemente del círculo vicioso durante los noventa (Figura 1) ${ }^{2}$. Nuestra preocupación es la de explicar las particularidades del porqué la recuperación ha sido difícil de asentar en Bolivia y, en términos más generales, ilustrar cuáles son las lecciones que se pueden derivar para las instituciones y los gobiernos que pueden tener la responsabilidad de tratar con este tipo de crisis en el futuro.

FIGURA 1

\section{BOLIVIA: CRECIMIENTO DEL PIB PER CAPITA \\ EN RELACIÓN A LAS ELECCIONES \\ E INCIDENTES DE VIOLENCIA POLÍTICA}

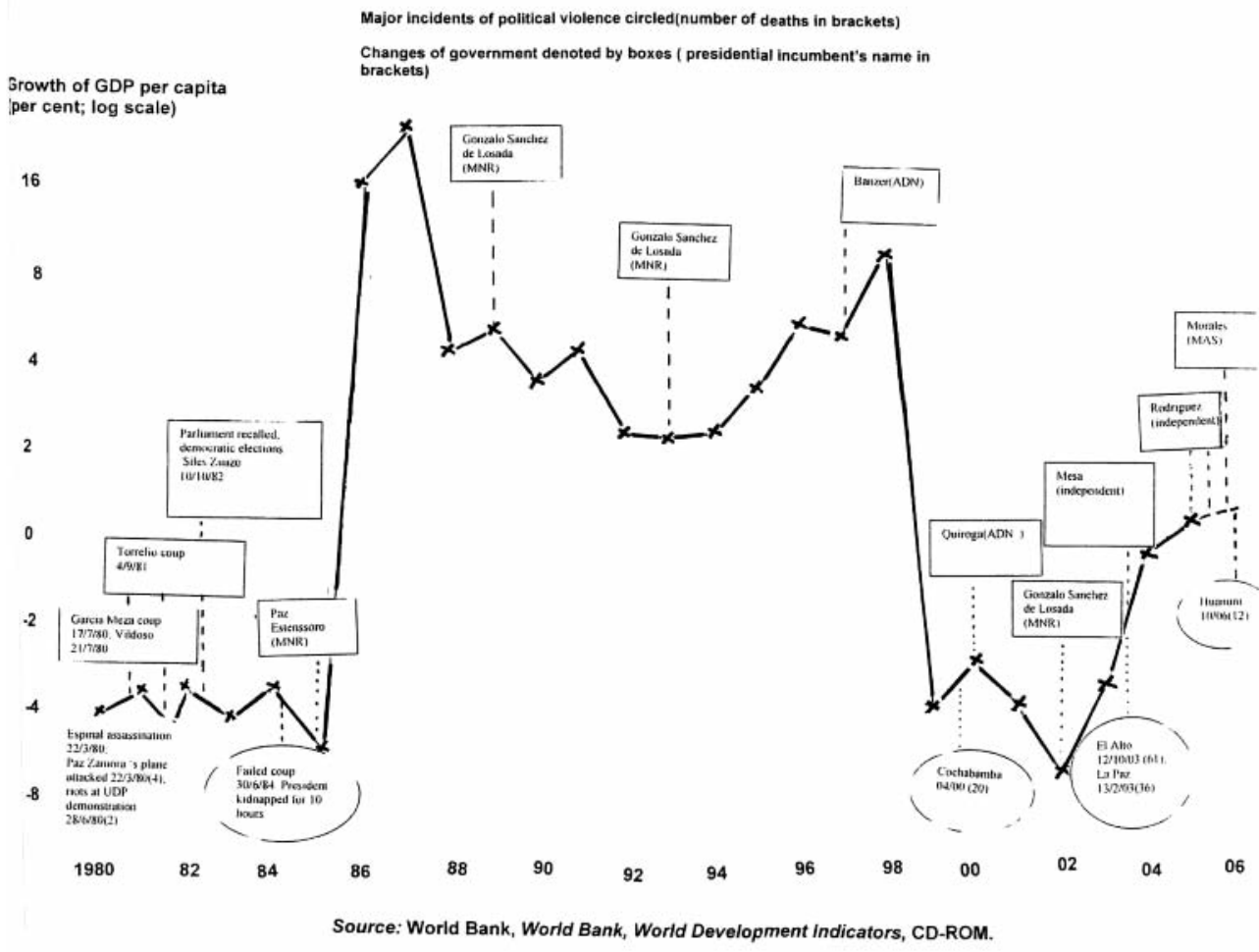

2 En 1996, el Director del FMI, Michel Camdessus, afirmó que el futuro económico de Bolivia estaba "seguro "y que el esperaba que Bolivia creciese hasta convertirse en un "Jaguar Andino", en analogía con los "Tigres del Este de Asia” (Lazarte Rojas 2005, p. 18). 
Un enfoque de las estrategias de recuperación de la crisis, frecuentemente atribuido al Fondo Monetario Internacional, explica la duración de las crisis y la eficacia de su recuperación por la adecuación técnica de los instrumentos de política económica utilizados para restablecer el balance externo -recortes de gasto, incrementos de impuestos, devaluación, etc. Sin embargo, este enfoque puede ser cuestionado ya que es técnicamente efectivo, puede no ser en la práctica políticamente factible. La demora del ajuste y la violencia política reflejada en el Cuadro 1 son, en parte, consecuencia de ello y, como resultado, lo que es óptimo en un sentido técnico puede dejar de serlo si las consecuencias políticas de esas medidas de política económica se tienen en consideración. En particular, puede ser necesario orientar más los ajustes políticos en favor de la gente pobre, que sean necesariamente acordes con el criterio de eficacia técnica, pero que persigan allanar los riesgos de protesta por parte de las personas perjudicadas por el ajuste.

Esta idea ha sido analizada por diversos estudios de la OCDE sobre las consecuencias sociales y políticas del ajuste (Bourguignon et al. 1992; Haggard et al. 1995). Sobre la base de los datos empíricos de la década de los ochenta e inicios de los noventa, concluyen estos estudios que aunque los criterios de factibilidad política son importantes para determinar la política de ajuste correcta, "un enfoque de equidad social no es necesariamente relevante para comprender las políticas del ajuste, debido a que los grupos políticamente más activos, normalmente no son los más pobres' ${ }^{3}$ (Haggard et al. 1995: 120). La implicación que se derivaría de este análisis es que una política más orientada a combatir la pobreza no necesariamente hubiera rescatado a Bolivia, o a cualquiera de los otros países incluidos en el Cuadro 1, de las consecuencias políticas de la austeridad fiscal. ¿Es esto [todavía] correcto?: éste es el asunto planteado en este artículo.

Nuestro enfoque es analizar la susceptibilidad de los países en desarrollo de caer en la "trampa de la pobreza", con lo cual una mala gestión de la crisis podría conducirlos a un proceso de declive de largo plazo. Recientemente, en la literatura del desarrollo han resurgido los modelos de la "trampa de la pobreza" como explicaciones de la persistencia de la pobreza en individuos y en países, aunque normalmente en ellos no se integran variables políticas. En términos generales, lo que se intenta explicar es la persistencia de la crisis en términos del desempeño de las instituciones políticas y de los factores económicos. De forma más específica, lo que se intenta indagar es cuándo y cómo los patrones anti-pobreza de la política pueden ser, en casos específicos como el de Bolivia, un instrumento efectivo para escapar de tales crisis.

La literatura original de la "trampa de la pobreza" o del círculo vicioso de la pobreza, que comienza con Nurkse (1953), utiliza un mecanismo causal que, en su

\footnotetext{
${ }^{3}$ Este juicio algo áspero se modifica en la siguiente página. No obstante, parte de la observación de que "el más insuperable determinante de la probabilidad de que los gobiernos se ajusten de forma rápida es el nivel de inequidad subyacente en la sociedad"... En países donde la inequidad es alta es más probable alcanzar desacuerdos insuperables en aspectos fundamentales sobre el ajuste (ibid., página 121).
} 
versión más simple, plantea que los bajos ingresos causan reducidos niveles de inversión, lo cual perpetúa el bajo ingreso (parte del lado izquierdo de la Figura 2). Versiones más recientes del circulo vicioso, incluyendo a Carter y May (1999), World Bank (2000) y Barrett y Carter (2006), han agregado mecanismos adicionales a este círculo vicioso de una naturaleza esencialmente económica ${ }^{4}$. Nuestro propio argumento desarrolla dicho enfoque, sugiriendo que Bolivia ha estado atrapada desde el 2000 en una trampa política de pobreza. Como en el modelo convencional de la pobreza, la pobreza permanece alta a causa de tasas de inversión bajas e inestables: pero lo que mantuvo las tasas de inversión bajas fue, en parte, un colapso de la confianza en el proceso político para el logro de la toma de decisiones democráticas y una erosión de la estructura institucional, lo cual, a su vez, fue agravado por la crisis económica. Las alternativas de política (tanto a nivel macro como micro) proporcionan un escape potencial de esta trampa; y será un objetivo adicional investigar en qué medida los eventos en Bolivia fueron consecuencia de no haber sabido (o podido) aprovechar estas oportunidades.

\section{FIGURA 2}

\section{VARIEDADES DE LA TRAMPA DE LA POBREZA}

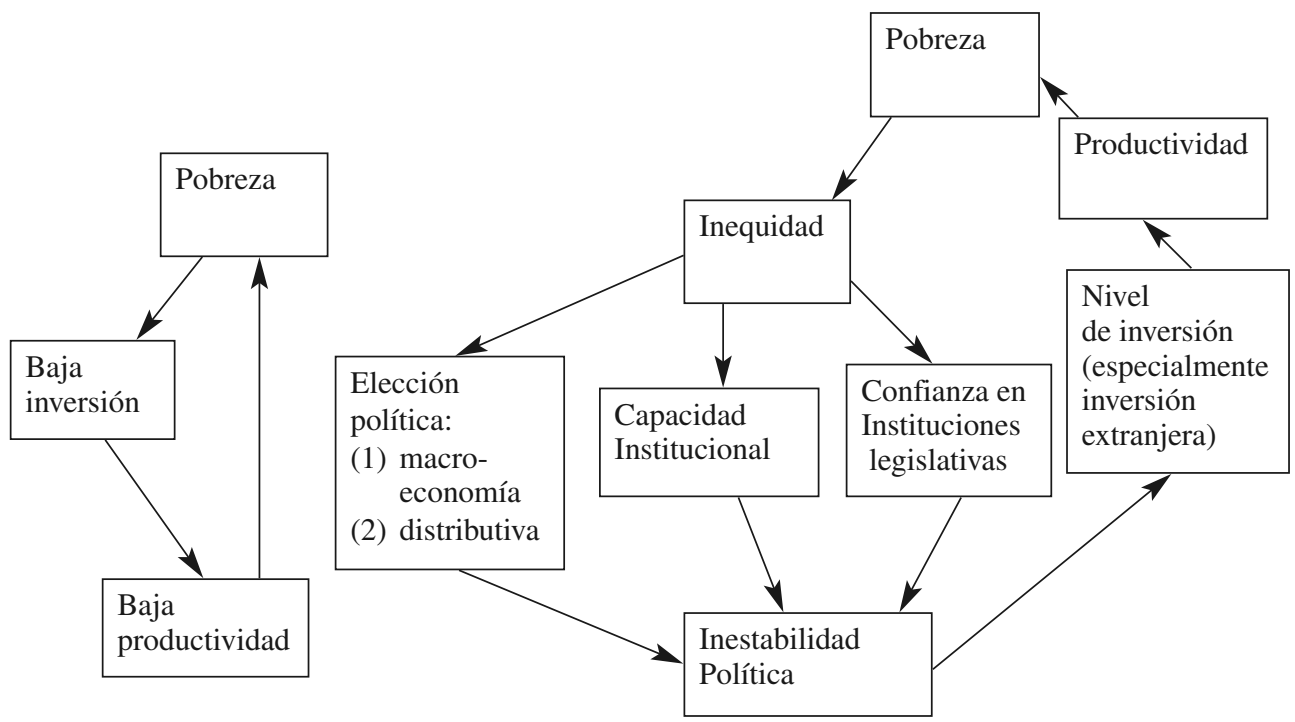

(a) En la económia básica

(b) En lo político-económico (según Nurkse 1953)

${ }^{4}$ Esto incluye vínculos desde la pobreza hacia la salud, la participación en mercados de trabajo, la capacidad de gestión del riesgo y la ausencia de un grupo de mecanismos de seguros. Para una discusión de los modelos recientes de la trampa de la pobreza ver Barrett y Carter (2006) o Mosley et al. (2009). 
El enfoque de la "trampa política de la pobreza", especificado en (b), forma el núcleo explicativo de nuestro trabajo. En el caso de Bolivia, dos factores adicionales específicos del país - los relacionados con la ayuda de los donantes y la concentración geográfica de la riqueza, la pobreza y la militancia política- juegan un importante papel tanto en el establecimiento de las condiciones iniciales como en la determinación de su evolución. Estas condiciones iniciales son examinadas en la Sección 2. En la sección 3, se comprobará el modelo de la trampa de la pobreza recogido en la Figura 2, con los datos disponibles para Bolivia. La sección 4 indaga si las variables del modelo de la trampa de la pobreza ayudan a explicar porqué Bolivia experimentó una crisis económica y política particularmente severa entre el 2000 y 2005, en comparación con otros países y, en particular, si otros países evitaron la crisis tomando algunas opciones que estaban disponibles pero que fueron descartadas en Bolivia. La sección 5 presenta las conclusiones.

\section{La crisis actual en su escenario de largo plazo}

El estado democrático de Bolivia, establecido en 1825, tiene un registro notorio de inestabilidad política, fragilidad y reversión hacia un modelo totalitario. Durante los 160 años de independencia y durante la hiperinflación de 1985 existieron cerca de 150 cambios de gobierno (Mesa, Gisbert y Mesa, 2003) y varios episodios de dictaduras militares. Durante los treinta años previos a 1985, una sucesión de gobiernos buscó romper las restricciones del desempeño de un país en su desarrollo persistentemente pobre a través de medidas estructurales, incluyendo una reforma agraria en 1952, la nacionalización de las minas en el mismo año y de las reservas naturales del gas en 1965, y los controles aplicados al tipo de cambio y a otros "precios claves". En el inicio del proceso de ajuste estructural al principio de los años ochenta, inicialmente, el gobierno resistió presiones para recortar el gasto y para el control de precios, y, el fallo de estos intentos eventualmente llevó a una de las mayores hiperinflaciones de los tiempos modernos, alcanzando su pico en Agosto de 1985, con un tasa de 24.000 por ciento.

Como era de esperar, el nivel de desinflación y liberalización requerida para el logro de la estabilización económica fue excepcionalmente dolorosa e involucró la eliminación virtual de la principal exportación de materia prima del país -la minería de estaño y plata ${ }^{5}$. Sin embargo, a través de este proceso, se lograron ciertos resultados tanto de estabilización económica como política: la inflación se controló, el crecimiento en la economía real fue positivo a partir de 1986 hasta el inicio de la crisis global en 2000, y la mayoría de los gobiernos elegidos en este periodo, contrariamente a todos los precedentes, completaron sus cuatro años de gobierno.

\footnotetext{
${ }^{5}$ Chávez (1992: 6) estima que de una fuerza de trabajo de 30 mil mineros del estaño, se retiraron cerca de 23 mil o el 70\%, Morales (1991) eleva este porcentaje hasta el 80\%. Ahora, sólo existen cerca de 2 mil mineros empleados en el estaño.
} 
De todas estas administraciones, la más radical en sus medidas de liberalización fue la de Gonzalo Sánchez de Lozada, un propietario de minas millonario ${ }^{6}$, que gobernó entre los años 1993 y 1997. En esta administración (bajo la denominada "Ley 21080"), se inició la privatización de los principales servicios (petróleo y gas, telefonía, electricidad y agua) bajo un régimen conocido como de "capitalización" y, se redujeron drásticamente los controles sobre los movimientos de capital y sobre el comercio.

Es necesario advertir sobre dos de las mayores amenazas de este aparente proceso de estabilización. La primera es que con el ajuste estructural, se produjo el desplazamiento desde un patrón de crecimiento basado en las exportaciones mineras hacia un patrón basado en las exportaciones de hidrocarburos (petróleo y gas natural), lo que planteó severos problemas en la creación de empleo y la reducción de la pobreza, debido a que la minería es intensiva en mano de obra mientras que el sector del gas natural es intensivo en capital (Cuadro 2). Además, el ajuste estructural estimuló un crecimiento muy escaso de la agricultura ${ }^{7}$, que también es un sector intensivo en mano de obra, haciendo que el problema empeorara. La segunda amenaza es que la herencia boliviana de altos niveles de inequidad, aún para los estándares de Latino América, se agravó por el ajuste estructural a través de dos vías políticamente cruciales. Las ganancias provenientes del ajuste estructural, esencialmente derivadas del comercio en los sectores del gas natural y de petróleo, no fueron para los indígenas Quechuas y Aymaras, sino para la población más rica del este y sudeste del país, donde los depósitos de gas y petróleo están localizados. Por su parte, las pérdidas del ajuste estructural se acumularon principalmente en los trabajadores, la mayor parte de origen indígena, de la región oeste del país. Como consecuencia, la inequidad (y especialmente la inequidad inter-étnica e inter-regional) creció a lo largo del periodo de estabilidad, entre 1986 al 2000, de una manera que fue abiertamente incrementada por las privatizaciones del gobierno, aunque esto no se tradujese en términos de pobreza. Los datos de pobreza en Bolivia son más recientes que los de la inequidad; no obstante, a partir de las medidas disponibles de pobreza, la incidencia de la pobreza y la pobreza medida por el acceso a salud y a los servicios de educación, parece que disminuyó en el periodo previo a 1999. De esta manera, el crecimiento en este periodo puede ser caracterizado como proclive a una cierta reducción de la pobreza (aunque sólo débilmente) (Klasen et al., 2001; Landa y Jiménez, 2005).

${ }^{6}$ La explicación es que Sánchez de Lozada habría sido el mayor ganador del proceso de privatización de la minería boliviana. Él habría comprado los activos de las pocas minerías que permanecieron siendo rentables después de la hiperinflación de 1985 y las habría combinado en una corporación privada rentable conocida como COMSUR.

${ }^{7}$ Existe una excepción muy importante a esta generalización en la industria de la coca, la cual creció rápidamente durante el periodo del ajuste estructural siendo intensiva en mano de obra. De Franco y Godoy (1990) mediante un modelo de equilibrio general computarizado calcularon que un incremento de $10 \%$ en la producción de cocaína suponía un incremento de $2 \%$ en el Producto Interno Bruto de Bolivia y una reducción de alrededor de 6\% en el desempleo del país. Painter (1994) p. 56. 


\section{CUADRO 2}

\section{BOLIVIA 1986-2000: MEDIDAS DE CRECIMIENTO, INEQUIDAD Y REDUCCIÓN POTENCIAL DE LA POBREZA}

\begin{tabular}{|c|c|c|c|c|c|c|c|c|}
\hline & \multicolumn{7}{|c|}{ Tasa de crecimiento promedio anuales } \\
\cline { 2 - 9 } & \multicolumn{2}{|c|}{ En toda la economía } & \multicolumn{2}{|c|}{ Agricultura } & \multicolumn{2}{c|}{ Minería } & \multicolumn{2}{c|}{ Petróleo y gas } \\
\cline { 2 - 9 } & PIB & $\begin{array}{c}\text { Empleo } \\
\text { (sector privado } \\
\text { solamente) }\end{array}$ & PIB & Empleo & PIB & Empleo & PIB & Empleo \\
\hline $1995-1998$ & 4.7 & -1.7 & 2.1 & n.d. & 0.0 & -1.1 & 5.6 & -0.6 \\
\hline $1999-2004$ & 2.1 & 1.0 & 2.9 & 2.7 & -1.6 & 0.1 & 9.5 & -0.3 \\
\hline
\end{tabular}

Fuentes: Instituto Nacional de Estadística, Anuario Estadístico 2004, tablas 4.02.01.01 y 3.04.05.01.

Los gobiernos reformistas en este periodo de ningún modo estaban desprevenidos de estas amenazas de largo plazo para la estabilidad económica y política. A partir de este periodo, tres medidas pueden verse como intentos particularmente importantes para paliar estas amenazas: la descentralización del poder político y de la responsabilidad fiscal a las regiones en 1994 (van Cott, 2002); el medianamente rápido crecimiento del empleo en el sector público (Cuadro 2), apoyado por el pionero Fondo de Inversión Social a partir de cuál se canalizaban fondos de la cooperación al desarrollo de infraestructura social para grupos de bajos ingresos; y, el también rápido crecimiento del sector de pequeños negocios por cuenta propia, apoyado por varios negocios de microfinanzas innovadores y arriesgados (Mosley 2001; Mosley y Marconi 2006), en los cuales Bolivia tiene un razonable derecho a ser pionero. Las dos últimas medidas aluden a riesgos compartidos con los donantes, de quienes Bolivia es mucho más dependiente que cualquier otro país de Latinoamérica.

Estas tendencias ayudaron a mejorar los indicadores sociales y permitieron que algunas agencias financieras internacionales sintieran una cierta euforia acerca de la transformaciones ocurridas en Bolivia: en 1996 el Director del FMI, Michel Camdessus, afirmó que el futuro económico de Bolivia estaba "asegurado" y que él esperaba que Bolivia creciera hasta convertirse en un "Jaguar Andino", en analogía con los "tigres" del Este de Asia ${ }^{8}$. Sin embargo, algunas debilidades permane-

\footnotetext{
${ }^{8}$ Lazarte Rojas (2005), p. 18.
} 
cieron durante los años noventa en la economía política del jaguar, a pesar de la inequidad y pobreza anteriormente identificadas. En primer lugar, a diferencia de Brasil y Argentina (nunca parecidos a los tigres del Este de Asia), el ajuste estructural en Bolivia no había producido el desplazamiento desde industrias no competitivas hacia industrias de exportación competitivas, tal y como las recomendaciones del "Consenso Washington" habían predicho. En las industrias pequeñas, de hecho, existió un desplazamiento en otro sentido ${ }^{9}$ y, en las industrias medianas y grandes emergió un sector privado poco flexible para llenar el vacío dejado por la nacionalización de las antiguas industrias estatales. En segundo lugar, los altos niveles de corrupción en el sector público persistieron, agravados por el proceso de privatización previamente discutido. En tercer lugar, aunque el sistema político había llegado a ser más estable, pues los cambios de gobierno inconstitucionales llegaron a ser menos frecuentes después de 1985, todavía no era representativo en el sentido de que ante un nuevo milenio, después de cerca de 50 años de acciones orientadas a la reducción de la pobreza en el marco de los sucesivos gobiernos, la participación de los pobres dentro el sistema político partidario continuaba siendo muy poco sólida: especialmente la de la mayoría Quechua y Aymara de la población. Esto factores hicieron que Bolivia fuese particularmente vulnerable a la embestida de una crisis externa, que finalmente golpeó al país en 1999.

\section{La crisis del periodo 2000-2005 y las explicaciones alternativas de su "persistencia"}

La crisis del "Este de Asia", llegó a Latinoamérica a través de Brasil a inicios de 1999, golpeó a Bolivia en la segunda mitad del año. Los siguientes cinco años fueron todos años de caída del PIB per capita (Cuadro 3). La incidencia de la violencia política severa comenzó el 2000, tuvo su clímax en el 2003 y luego disminuyó, aunque todavía continúa la tensión en la medida en que la incidencia de manifestaciones se prolonga hasta la actualidad. Entre el 2000 y el 2005 existieron en Bolivia cuatro nuevos presidentes, y por tanto, la estabilidad económica y política analizada en la sección anterior, se había disipado.

\footnotetext{
${ }^{9}$ Rhyne (2001), tabla 2.1, afirma que entre 1985 y 1989 la participación de las manufacturas en el sector informal se reduce desde $31 \%$ a $17 \%$, mientras que la participación del comercio y los servicios creció desde 35\% hasta 56\%. Ver también el artículo de Miguel Lora en PULSO, número 187 (7-13 March, 2003), páginas 11-14, que apoya la idea de que el microcrédito "que supuestamente fue desarrollado para apoyar a las empresarios privados, dio incentivos sólo a la economía informal y el contrabando (ibid. página 11).
} 
TABLA 3

BOLIVIA: EVOLUCIÓN DE LA ECONOMÍA EN RELACIÓN A LAS ELECCIONES Y LA VIOLENCIA POLÍTICA, 1997-2005

\begin{tabular}{|c|c|c|c|c|c|}
\hline & 1997 & 1998 & 1999 & 2000 & 2001 \\
\hline \multicolumn{6}{|l|}{ Economía real } \\
\hline $\begin{array}{l}\text { Producto } \\
\text { PIB per capita (en dólares) }\end{array}$ & & 1070 & 1023 & 1016 & 949 \\
\hline $\begin{array}{l}\text { Crecimiento del PIB real (\%): } \\
\text { Absoluto } \\
\text { Per capita }\end{array}$ & & 5.2 & $\begin{array}{c}0.4 \\
-4.6\end{array}$ & $\begin{array}{c}2.4 \\
-0.7\end{array}$ & $\begin{array}{c}0.0 \\
-6.6\end{array}$ \\
\hline $\begin{array}{l}\text { Inversión } \\
\text { Inversión/PIB (\%) }\end{array}$ & & 23.8 & 18.4 & 17.3 & 17.0 \\
\hline Inversión extranjera/PIB (\%) & & 11.9 & 12.9 & 10.7 & 8.7 \\
\hline Ahorro/PIB(\%) & & 16.0 & 12.5 & 11.8 & 12.7 \\
\hline \multicolumn{6}{|l|}{$\begin{array}{l}\text { Finanzas Públicas } \\
\text { Déficit Fiscal/PIB (\%) }\end{array}$} \\
\hline $\begin{array}{l}\text { Indicadores de Pobreza } \\
\text { Tasa de desempleo urbano (\%) }\end{array}$ & & 5.3 & 6.1 & 6.8 & 7.3 \\
\hline $\begin{array}{l}\text { Estimación de la incidencia } \\
\text { de la pobreza }(\%)\end{array}$ & $65.6(1)$ & & 62.3 & 65.5 & 64.3 \\
\hline $\begin{array}{l}\text { Coeficiente de Gini } \\
\text { de inequidad }(\%)\end{array}$ & & 62,7 & 62,2 & 64,4 & 61,5 \\
\hline \multicolumn{6}{|l|}{$\begin{array}{l}\text { Cambios políticos } \\
\text { e incidencia de la violencia }\end{array}$} \\
\hline Cambios de gobierno & $\begin{array}{l}\text { Elección } \\
\text { ganada } \\
\text { por Banzer }\end{array}$ & & & & $\begin{array}{l}\text { Sucesión del } \\
\text { Vicepresidente } \\
\text { Quiroga por } \\
\text { enfermedad } \\
\text { y posterior } \\
\text { fallecimiento } \\
\text { de Banzer }\end{array}$ \\
\hline $\begin{array}{l}\text { Incidencia } \\
\text { de la violencia politica: } \\
\text { Muertes relacionadas } \\
\text { con la violencia política }\end{array}$ & & & & $\begin{array}{l}\text { Febrero-Abril: } 4 \text { muertes } \\
\text { en la "guerra del agua" } \\
\text { en Cochabamba } \\
\text { y en otras localidades. } \\
18 \text { Septiembre al } 4 \text { de } \\
\text { Octubre: } 7 \text { muertes }\end{array}$ & $\begin{array}{l}\text { 21-30 Junio: } \\
2 \text { muertes }\end{array}$ \\
\hline $\begin{array}{l}\text { Días perdidos por huelgas } \\
\text { y manifestaciones } \\
\text { Mediciones del INE } \\
\text { Nuestras mediciones }\end{array}$ & & & & & \\
\hline
\end{tabular}

Fuente: Instituto Nacional de Estadistica; Banco Santa Cruz/Muller y Asociados, Estadísticas socio-económicas 2001, 2003. Estimaciones de la incidencia de la de UDAPE. Las "muertes relacionadas con violencia polí- 
TABLA 3 (continuación)

BOLIVIA: EVOLUCIÓN DE LA ECONOMÍA EN RELACIÓN A LAS ELECCIONES Y LA VIOLENCIA POLÍTICA, 1997-2005

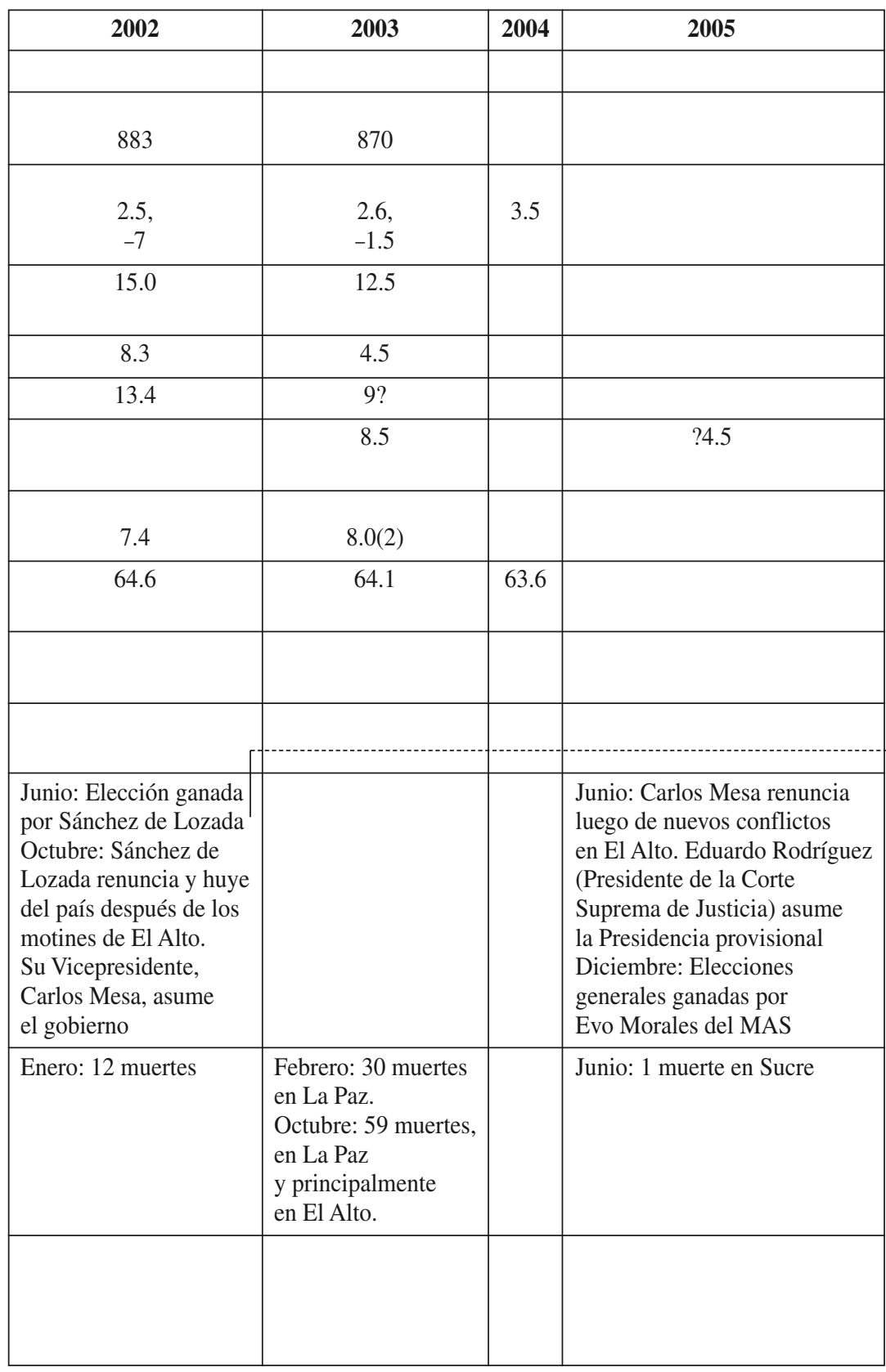

Comentario: Las elecciones se realizaron en el 2002 y ese mismo año GONI tomó posesión como presidente de Bolivia.

tica" y los "días perdidos por huelgas y manifestaciones" son nuestras propias medidas, elaboradas en el Anexo. 
Para comprender la interrelación entre el colapso de la economía y la estabilidad política, comenzamos recapitulando los principales incidentes de violencia política registrados en la penúltima columna del cuadro.

En abril del 2000, se produjeron motines y manifestaciones en contra de las políticas económicas del gobierno en varias de las zonas centrales y del oeste de Bolivia, las cuales fueron organizadas por la CSUTCB (Confederación Sindical Única de Trabajadores Campesinos de Bolivia), una unión de campesinos y pequeños agricultores. Un componente particular de la protesta fue el incremento (por encima del $275 \%$ ) en los precios impuestos por la autoridad del agua en Cochabamba, privatizada bajo la Ley 21080. En el intento de suprimir estos motines, cuatro personas murieron (Pulso, números 37 al 39, del 7-27 de Abril del 2000).

En febrero de 2003, el gobierno propuso ampliar hacia las rentas más bajas el alcance del impuesto sobre la renta personal, incluyendo varias categorías de empleados asalariados, previamente no cubiertas. Todo ello en preparación a la llegada de una misión del FMI, la cual se esperaba que proporcionase a Bolivia un crédito PRGF (Poverty Reduction and Growth Facility) de 3.9 millones de dólares americanos, en respuesta a la reducción creíble del déficit fiscal del 8,5\% del PIB que registraba el país (Miguel Lora, Pulso, 7 al 13 de febrero de 2003, pág. 11). Antes de que la propuesta pudiera ser implementada, ésta se filtró a través de la prensa. Así comenzaron los motines en la Plaza Murillo, plaza de la ciudad de La Paz donde se ubica el palacio presidencial. Las protestas fueron protagonizadas primero por estudiantes que apedrearon el palacio de gobierno. Los policías, que estaban entre los trabajadores con menores salarios y con riesgo de ser afectados por el nuevo impuesto propuesto, no defendieron el palacio y permanecieron al margen. Entonces, el gobierno envió militares para disciplinar a los policías, generando un tumulto que ocasionó la muerte de 20 a 30 personas $^{10}$.

En octubre de 2003, hubo una confrontación entre las fuerzas de seguridad del país y la población civil. A dicha confrontación siguió el anuncio de una huelga general, anunciada por la COB (Central Obrera Boliviana), en El Alto y La Paz, en protesta contra el plan del gobierno para exportar gas natural a través de Chile. El 13 de Octubre, los militares bajo las órdenes del gobierno, rompieron por la fuerza el bloqueo realizado cerca de los depósitos de Petróleo en Senkata, en el lado sur de la ciudad de El Alto. Esta acción generó una escalada de motines más generales en la ciudad de El Alto, durante los cuales murieron al menos 59 personas entre el 13 y 14 de octubre ${ }^{11}$. El 14 de octubre, el Vicepresidente, Carlos Mesa, dejó el gobierno como consecuencia de las muertes ocurridas y, el 17 de octubre, cuando el presidente Sánchez de Lozada huyó del país escapando de lo que habría

${ }^{10}$ Una detallada cobertura de estos incidentes la da en Pulso, número 183, 7-13 Febrero de 2003 y, en La Prensa del 12 de Febrero de 2003.

${ }^{11}$ Una revisión detallada de los eventos del "Octubre Negro" la da en un número especial de $L a$ Prensa del 23 de Diciembre de 2003. Algunos observadores también los relatan en libros, por ejemplo, Garcia, Prada y Tapia (2004). 
llegado a ser un linchamiento en masa. Mesa fue nombrado presidente interino. Sus 21 meses de administración transcurrieron no sin incidentes de violencia, pero nunca al nivel de aquellos del 2003.

¿Por qué ocurre la violencia política? Considerando las posibles causas, es difícil mejorar el recuento dado, a raíz de las protestas de Febrero de 2003, por el Presidente del Banco Central de Bolivia, Juan Antonio Morales:

"(Los incrementos en) la deuda externa de Bolivia y en la ayuda externa que apuntaban a la reducción de la pobreza, beneficiaron principalmente a la clase media. Aún cuando se lograron mejoras en el Índice de Desarrollo Humano y en la disminución de la pobreza, la distribución de la renta se deterioró, tal como sucedió en toda Latinoamérica. El deterioro de la distribución de la renta en un país pobre y supremamente politizado, está tal vez entre las principales causas de la tragedia de Febrero"12.

Sin embargo, muchos países que también padecieron altos niveles de inequidad, incluyendo algunos en Latinoamérica, no padecieron niveles tan altos de conflicto social latente. Por tanto, un aspecto que tiene que ser explicado es porqué una causa plausible dada derivó en consecuencias particularmente graves en Bolivia. En segundo lugar, es útil enmarcar las explicaciones de los gobernantes dentro de un cuadro más amplio de causas y efectos, tomando en cuenta no sólo las causas de la violencia, sino también sus consecuencias en términos de reducción en las tasas de inversión y, por tanto, menor potencial productivo y menores ingresos.

Esto se recoge en el modelo del "círculo vicioso político", presentado en la Figura 1, que define los vínculos entre la confianza política, la violencia y la pobreza:

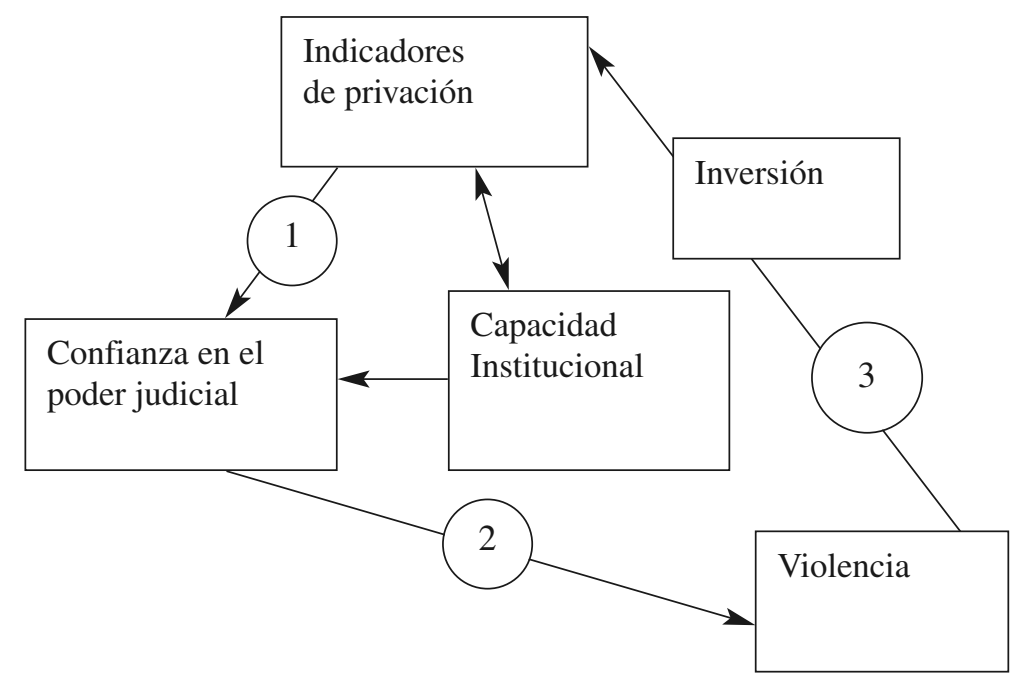

${ }^{12}$ Juan Antonio Morales, 'Qué le ha pasado a Bolivia?' (What has happened to Bolivia?), Pulso, 14-20 March 2003, page 7. 
El vínculo desde la privación hacia la violencia fue particularmente fuerte en Bolivia, debido a los siguientes cuatro factores:

1) "La desinstitucionalización" o la "descapitalización política" debido a la decadencia de varias de las instituciones diseñadas para promover la justicia y, en particular, para proteger los intereses de los débiles, por lo que el deterioro de la distribución del ingreso llegó a parecer particularmente dañino para los excluidos.

2) La metamorfosis de los partidos políticos: especialmente en los años de recesión (2000-2005), los partidos políticos (reconocidos por su debilidad política como protectores de sus intereses) se trasladaron desde el parlamento hacia otros canales de influencia.

3) El enfoque geográfico del descontento: mucha de la ira sentida por los pobres tuvo una localización (El Alto), donde la violencia pudo ser organizada y desplegada con una razonable probabilidad de que la acción extraparlamentaria podría lograr cambios políticos de largo plazo.

4) Oportunidades desperdiciadas: aún frente a factores de extrema vulnerabilidad, identificados en (1) a (3), las opciones de política económica para tratar los conflictos sociales fundamentales existentes, que habían sido exitosamente probadas en otros contextos, pudieron haber sido probadas en Bolivia, pero no lo fueron. Dada esta falta de visión, a las instituciones financieras internacionales (de las cuáles Bolivia era fuertemente dependiente; incluso más que la mayoría de los países afectados por la crisis) les corresponde asumir cierta responsabilidad.

La inestabilidad política ahuyentó el capital extranjero y la pérdida de la inversión perpetuó el bajo ingreso, completando el círculo vicioso. Habiendo proporcionado una exposición razonable para apoyar estas hipótesis, en el cuadro 4, presentamos evidencia de las mismas.

\section{"Desinstitucionalización”}

El impacto visible de la inequidad se agravó, en varias formas, por la decadencia institucional o la descapitalización institucional, o la "desintitucionalización", como es conocido este fenómeno en Bolivia. Un aspecto principal de este fenómeno es la corrupción y, específicamente, la corrupción emergente a partir del proceso de capitalización. La corrupción supuso un problema distributivo, por el hecho de que los factores de producción no estaban siendo distribuidos con criterios de eficiencia sino con una mala gestión política con consecuencias negativas tanto fiscales como distributivas (prueba de ello es que, en el 2003, las empresas privatizadas del 
gas y el petróleo estaban pagando en impuestos sobre el beneficio menos de la mitad de lo que pagaban antes de la privatización ${ }^{13}$ y que las ganancias provenientes de la corrupción se acumularon principalmente en los ricos y no en los pobres. Las enormes ganancias de los beneficiarios de la privatización del sector del gas y del petróleo, en una época de austeridad para la población (y de incrementos en el impuesto sobre la renta especialmente), lo cual causó que el aparentemente extraño tema de las exportaciones del petróleo vía Chile, llegara a incendiar la llama de octubre de $2003^{14}$.

Un segundo elemento de la decadencia institucional, íntimamente relacionado con el declive en la inversión recogido en el cuadro 3, se basa en el sector financiero. La recuperación del sector bancario, fuertemente basada en las microfinanzas ${ }^{15}$, llegó a contaminarse gradualmente durante el boom de finales de los noventa, en particular, por la entrada en el mercado de las casas de crédito al consumo, que prestaron sin una apropiada valoración o garantía (Rhyne, 2002). Todo ello agobió a muchos hogares y pequeños negocios con una carga de deuda que no pudieron soportar. Cuando la recesión golpeó al país, muchos prestatarios entraron en mora (la tasa promedio de impago en el sector de las microfinanzas creció desde $2 \%$ a $12 \%$ entre 1997 y 2001) y, algunos de los más políticamente poderosos se apoyaron en la administración de Banzer del 1999-2001, en algunos casos colectivamente como asociación de deudores, para anular sus deudas. Algunos de los más leales clientes del gobierno tuvieron éxito en este empeño y, con ello, la disciplina financiera se debilitó $^{16}$. Debido a que los bancos no estaban recuperando sus préstamos, los cré-

${ }^{13}$ Rolando Morales, La Prensa, 12 de Febrero de 2003, p. 6. "La Confederación de Empresarios Privados de Bolivia", Morales agrega, "indicando que la caída de los ingresos fiscales del país [entre finales del 2001 y finales del 2002, que había causado un recorte en los ingresos y requirió que el FMI fuese llamado] fue de 7,3\% y estuvo causada principalmente por la caída del $25,4 \%$ en los ingresos fiscales del sector hidrocarburos (petróleo y gas), en el mismo periodo".

${ }^{14}$ En el 2003, esto se agravó por dos factores. Primero, muchas de las ganancias provenientes, en particular, del crecimiento del sector del petróleo, beneficiaron a regiones ya ricas del sudeste y del este del país, en lugar de a la regiones pobres del oeste (esto se hubiera sentido como particularmente intenso durante el periodo de incremento de los precios del gas y el petróleo desde el inicio de la guerra de Iraq en el 2003). Segundo, el Presidente Gonzalo Sánchez de Lozada (persona que durante el periodo de ajuste estructural acumuló muchos de los activos más rentables provenientes de una industria minera colapsada), fue por sí mismo un temprano ejemplo representativo de la clase que se había formado y exportado una gran cantidad de dinero fuera de Bolivia como consecuencia del proceso de privatización.

${ }^{15}$ La institución microfinanciera BancoSol, inicialmente nacida de una organización no gubernamental, financiada por USAID, fue durante mediados de los noventa el banco más rentable de Bolivia.

${ }^{16}$ Esta generalización es verdad como tendencia pero no es ni remotamente cierta para todas las instituciones financieras. En particular, cuatro instituciones microfinancieras (FIE, Caja los Andes, PROMUJER y CRECER) resistieron el incremento de tasas de impago durante la recesión, en parte, debido a que su gestión gerencial aguantó la presión del gobierno por cancelar la mora, y a que estaban mejor diseñadas para afrontar shocks (por ejemplo, a través de la cuenta interna del modelo de banca comunal en las dos últimas instituciones nombradas, que actuó como un mecanismo de seguro) y, en parte, debido a la intensa lealtad institucional de los clientes de todas estas instituciones (Marconi y Mosley, 2006). 
ditos del sector bancario y el nivel de inversión doméstica, llegaron a estar crecientemente restringidos: el colapso de la inversión doméstica, recogido en el cuadro 3 , está íntimamente relacionado con el colapso de la disciplina en los bancos ${ }^{17}$. Si bien un shock inicial en la inversión es una característica común de muchas recesiones, el que este shock derive o no en un colapso, depende crucialmente del comportamiento del sector bancario. En Indonesia, otro país fuertemente golpeado por la crisis del "Este de Asia", los principales bancos de microfinanzas no relajaron la disciplina financiera y la inversión de las empresas pequeñas se incrementó a lo largo de la recesión, actuando como un factor anti-cíclico (Patten y Rosengard, 2001; Marconi y Mosley, 2006). La habilidad del sector financiero de Bolivia para salir de la crisis dependerá de que el gobierno del MAS llevase a cabo o no su promesa electoral de cancelar todas las deudas morosas de las microfinanzas.

Un tercer elemento de la desinstitucionalización fue la erosión de los derechos civiles. Una ilustración importante de este proceso fue la negativa del Presidente Sánchez de Lozada, en Septiembre del 2003, de reelegir a Ana Maria Romero de Campero en el cargo de Defensora del Pueblo ("ombudsman"), establecido en 1998 como uno de los logros del gobierno de Banzer. La señora Romero, una persona que había pasado cinco años apoyando el cumplimento de la ley en el campo de los derechos civiles, fue cesada de su cargo en un periodo de extrema presión sobre estos derechos, por orden del Presidente -en contra de los consejos de muchos de sus senadores y diputados ${ }^{18}$. El incidente fue crucial para encender la violencia de Octubre de $2003^{19}$.

Durante la recesión, los procedimientos legales en su conjunto, llegaron a ser incapaces de proteger de una manera justa o equitativa los derechos civiles o los derechos a la propiedad privada. En el marco de un sistema donde la justicia parecía incapaz de afrontar los pecados de la corrupción y de la evasión de impuestos, resultaba obvio, no sólo para los socialmente excluidos, que las instituciones existentes no estaban funcionando. Este pudo ser un factor de peso en la promoción del cambio político.

\section{La metamorfosis de los partidos políticos}

Es bien conocido que en América Latina los partidos políticos, por varias razones, han aceptado los ideales democráticos ortodoxos (Foweraker, Landman y Harvey 2003: capítulo 5). Sin embargo, en Bolivia tanto la inestabilidad del sistema partidario como el grado en el que los partidos han ido más allá del parlamento, excede la

${ }^{17}$ En la medida en que las microfinanzas reducen la pobreza, la caída del microcrédito descrita aquí también contribuyó directamente a incrementar la pobreza en los años 1999-2004.

${ }^{18}$ Entrevista a un senador del MNR, el 21 de Septiembre del 2005.

19 Ver La Prensa, 23 de diciembre de 2003, y también la entrevista con Ana María Romero de Campero en Pulso, número 218, 10-16 de octubre de 2003, que caracteriza Bolivia como 'democradura' (mitad democracia, mitad dictadura). 
norma Latinoamericana. El MNR (Movimiento Nacionalista Revolucionario), el arquitecto de las reformas agrarias de 1952 y de los programas de nacionalización, dio cuerpo a una retórica en favor de los pobres por un periodo considerable. Pero en su retorno al poder, en la emergencia de la hiperinflación de 1985, fue forzado a anteponer la estabilización a la redistribución. Durante todo el periodo de ajuste estructural entre 1986 y 1999, los partidos principales, todos en lo esencial partidos del centro-derecha favorables al capital internacional, a la liberalizacion y a los Estados Unidos, tuvieron que entrar en coaliciones para gobernar, 'turnando las posiciones, como buenos amantes, a veces en un lugar y otras en otro, alguna vez arriba y otras abajo', como lo describió el periodista y diputado Cayetano Llobet. Los intercambios involucrados en la creación de estas coaliciones impusieron límites severos no solamente a la capacidad de formar decisiones racionales de política fiscal, sino aun más en su capacidad de representar de cualquiera manera creíble los intereses de los [socialmente] excluídos.

Como lo ilustra el cuadro 4, estas oscilaciones políticas cesaron en los últimos años. Ninguno de los tres partidos, que compartieron el poder durante todo el periodo de ajuste estructural, sobrevivió hasta las elecciones de 2005 como candidato creíble, y el partido que ahora esta en el gobierno, el MAS (Movimiento al Socialismo) tenía hasta 2002 solamente el 2\% de los escaños en la Camara de Diputados $^{20}$. En las elecciones de 2002, el MAS y el MIP (Movimiento Indígeno Pachacuti), bajo el liderazgo de Felipe Quispe lograron un avance radical. Ambos partidos estaban encabezados por gente aymara comprometida con la justicia social a través del cambio constitucional, del proteccionismo económico y de una estrategia de "recapturar" los recursos naturales del país para la gente. A diferencia de los partidos anteriores de élite, éstos son partidos capaces de conseguir una transformación electoral a pesar de carecer de organización nacional sólida, máquinaria de publicidad o acceso a los consultores internacionales (Lazarte Rojas, 2005: 358). El embajador de EE.UU. trató, de forma inadecuada, de influir en las elecciones de 2002 recomendando al electorado que no votase al MAS, una política que fracasó de manera espectacular ${ }^{21}$. A partir de la elección de 2002, el gobierno y la oposición, de forma similar, abandonaron cualquier pretensión de respetar las reglas del juego parlamentario. Quispe, en nombre del MIP, se comprometió a renovar las tácticas de control policial de $2002^{22}$. Morales trató de complementar o reemplazar

${ }^{20}$ El primer intento serio al tratar representar los intereses de los [socialmente] excluídos fue CONDEPA. Dirigido por un profesional 'blanco' que apoyó la reducción de la pobreza por motivos de compasión, alzó la conciencia de la clase media, pero fue víctima de acusaciones de corrupción (Llobet 1998) y no pudo consolidar su rápida subida inicial.

${ }^{21}$ El 26 de junio de 2003, el embajador Manuel Rocha dijo:

'Quisiera advertir al electorado boliviano que si elige candidatos que tratan de hacer que Bolivia se convierta de nuevo en exportadora de cocaína, ese resultado sería perjuicial para los flujos futuros de ayuda de los EE.UU. (en la columna Usted Elige en La Prensa, 27 de junio de 2002. Ver tambien Lazarte Rojas, 2005: 373).

${ }^{22}$ Ver PULSO, número 399 (21-27 de Abril de 2000). 
CUADRO 4

PARTIDOS EN LA CÁMARA DE DIPUTADOS BOLIVIANA, 1997-2005

\begin{tabular}{|c|c|c|c|c|c|c|c|}
\hline \multicolumn{4}{|c|}{$\begin{array}{l}1997 \\
\text { 'Coalición gobernante' }\end{array}$} & \multicolumn{4}{|c|}{ 'Partidos de oposición' } \\
\hline Partido & Jefe & $\begin{array}{l}\% \\
\text { voto }\end{array}$ & $\begin{array}{l}\text { Escaños } \\
\text { (diputados) }\end{array}$ & Partido & Jefe & $\begin{array}{l}\% \\
\text { voto }\end{array}$ & $\begin{array}{l}\text { Escaños } \\
\text { (diputados) }\end{array}$ \\
\hline AND-NFR & $\begin{array}{l}\text { Hugo } \\
\text { Banzer } \\
\text { Suárez }\end{array}$ & 22.2 & & CONDEPA & $\begin{array}{l}\text { Remedios } \\
\text { Loza } \\
\text { Alvarado }\end{array}$ & 17.1 & \\
\hline $\begin{array}{l}\text { Movimiento } \\
\text { de la Izquierda } \\
\text { Revolucionaria } \\
\text { (MIR) }\end{array}$ & $\begin{array}{l}\text { Jaime } \\
\text { Paz } \\
\text { Zamora }\end{array}$ & 16.7 & & $\begin{array}{l}\text { Eje } \\
\text { Pachacuti }\end{array}$ & $\begin{array}{l}\text { Ramiro } \\
\text { Barrenechea }\end{array}$ & 0.8 & \\
\hline $\begin{array}{l}\text { Movimiento } \\
\text { Revolucionario } \\
\text { Nacional } \\
\text { (MNR) }\end{array}$ & $\begin{array}{l}\text { Juan } \\
\text { Carlos } \\
\text { Durán }\end{array}$ & 18.2 & & $\begin{array}{l}\text { Movimiento } \\
\text { al Socialismo } \\
\text { (MAS) }\end{array}$ & Evo Morales & 3.2 & \\
\hline \multicolumn{4}{|c|}{$\begin{array}{l}2002 \\
\text { 'Coalición gobernante' }\end{array}$} & \multicolumn{4}{|c|}{ Partidos de oposición } \\
\hline Partido & Jefe & $\begin{array}{l}\% \\
\text { voto }\end{array}$ & $\begin{array}{l}\text { Escaños } \\
\text { (diputados) }\end{array}$ & Partido & Jefe & $\begin{array}{l}\% \\
\text { voto }\end{array}$ & $\begin{array}{l}\text { Escaños } \\
\text { (diputados) }\end{array}$ \\
\hline $\begin{array}{l}\text { Movimiento } \\
\text { Revolucionario } \\
\text { Nacional } \\
\text { (MNR) }\end{array}$ & $\begin{array}{l}\text { Gonzalo } \\
\text { Sánchez } \\
\text { de Lozada }\end{array}$ & 22.4 & 36 & $\begin{array}{l}\text { Movimiento } \\
\text { al Socialismo } \\
\text { (MAS) }\end{array}$ & Evo Morales & 20.9 & 35 \\
\hline $\begin{array}{l}\text { Movimiento } \\
\text { de la Izquierda } \\
\text { Revolucionaria } \\
\text { (MIR) }\end{array}$ & $\begin{array}{l}\text { Paz } \\
\text { Zamora }\end{array}$ & 16.3 & 26 & $\begin{array}{l}\text { Movimiento } \\
\text { Indígena } \\
\text { Pachacuti } \\
\text { (MIP) }\end{array}$ & $\begin{array}{l}\text { Felipe } \\
\text { Quispe } \\
\text { 'Mallku' } \\
\text { [The Condor] }\end{array}$ & 6.0 & 6 \\
\hline $\begin{array}{l}\text { Nueva Fuerza } \\
\text { Republicana } \\
\text { (NFR) }\end{array}$ & $\begin{array}{l}\text { Reyes } \\
\text { Villa }\end{array}$ & 20.9 & 25 & Otros partidos & & 9 & 11 \\
\hline \multicolumn{8}{|l|}{2005} \\
\hline & & & & MAS & Evo Morales & 54 & \\
\hline & & & & PODEMOS & $\begin{array}{l}\text { 'Tutu' } \\
\text { Quiroga }\end{array}$ & 32 & \\
\hline & & & & UN & $\begin{array}{l}\text { Samuel } \\
\text { Doria } \\
\text { Medina }\end{array}$ & 10 & \\
\hline & & & & Otros partidos & & & \\
\hline
\end{tabular}

Fuente: Van Cott (2003), table 1, p. 753; Lazarte Rojas (2005), appendix. 
el proceso parlamentario con un encuentro entre el presidente y un grupo amplio de intereses de la sociedad civil, obreros, pequeños propietarios, incluido cocaleros, jubilados, clientes de servicios financieros ${ }^{23}$, y el presidente Sánchez de Lozada no solamente limitó su diálogo con Morales (todavía el dirigente del sindicato de cocaleros) al asunto de la erradicación de la coca, sino que eligió el mes de enero de 2003, justo cuando las posibilidades de una solución pacífica empezaban a ser problemáticas, al lanzar un ataque preventivo contra los cocaleros del Chapare, en el que murieron trece personas. A partir de este momento, las probabilidades para establecer la paz fueron mínimas.

De esta manera, frente a las alteraciones promovidas por la crisis global, no sólo (como vimos anteriormente) se deshicieron muchas de las instituciones que habrían podido solucionar los problemas, sino que el proceso parlamentario que también los habría podido resolver, fue eludido por todos los protagonistas de la situación política.

El mérito de Evo Morales fue el hecho de persuadir, no solamente a sus aliados de habla aymara, sino también a gran parte de la clase media (al menos en el altiplano) para apoyar sus esfuerzos dentro de la esfera parlamentaria ${ }^{24}$. Este proceso empezó en el año 2003, como consecuencia de un pulso sostenido, en forma de "juego de confianza", con Sánchez de Lozada. Morales persuadió no solamente a este grupo clave, sino también a la mayor parte de la clase media urbana, para que abandonase sus lealtades tradicionales, demandando su apoyo a un hombre al que todos los medios de comunicación pro-gobierno pintaban como un narcotraficante.

${ }^{23}$ Reportado en PULSO, 10-16, Enero 2003, p. 4.

${ }^{24}$ Llevamos a cabo una encuesta en La Paz y otra en El Alto durante septiembre de 2005 (Mosley, 2006) con el propósito de comprender el vínculo entre confianza política y confianza entre personas. En esta encuesta se entrevistó a 105 personas escogidas al azar desde los grupos de microempresarios, obreros y profesionales. Los resultados indican que la proporción de profesionales que intentaban (en septiembre de 2005) votar a Morales era más o menos equivalente al porcentaje de microempresarios y obreros que también le intentaban votar:

\begin{tabular}{|l|c|c|c|c|c|}
\hline & \multicolumn{4}{|c|}{ Intención, Septiembre } & Resultado, Diciembre \\
\hline & Microempresarios & Obreros & Profesionales & Todos & \\
\hline Quiroga & 6.5 & 5.7 & 30.6 & 14.7 & 29 \\
\hline Doria Medina & 6.5 & 17.1 & 5.6 & 9.8 & 17 \\
\hline Morales & 32.3 & 48.6 & 36.1 & 39.2 & 44 \\
\hline Otros & & 2.9 & 2.0 & 2.0 & 10 \\
\hline No responde & 22.6 & 25.7 & 24.5 & 24.5 & \\
\hline
\end{tabular}

Fuente: Mosley 2006. 


\section{Pobreza, desigualdad y militancia}

A menudo se explica la crisis boliviana con la idea de que 'la pobreza está por debajo de todo' (es la causa fundamental de todo). Pero qué tipo de pobreza, o cambio en el nivel de pobreza, tiene posibilidades de causar el conflicto, o de parar las políticas de estabilización? La literatura de 'economía del conficto' aporta poco sobre este tema, confirmando de manera empírica que los niveles bajos de seguridad alimentaria están relacionados con probabilidades más altos de conflicto ${ }^{25}$ (Auvinen y Nafziger, 2002; Collier, 2002, 2004). Sin embargo, la mayoría de estos estudios no diferencian entre las medidas múltiples de pobreza que ahora se utilizan. La literatura de ciencias políticas enfatiza que una caída repentina en el nivel establecido de consumo, es el tipo de impacto que tiene mayores posibilidades de desencadenar el enfado público, y de ahí el conflicto (Gurr, Why Men Rebel; Goodhand, 2003, etc).

En relación a Bolivia, podemos empezar con un examen de los indicadores y de las ubicaciones del conflicto. Los indicadores se encuentran en el cuadro 5. La medida de incidencia de la pobreza, probablemente, cayó ligeramente a lo largo de los noventa (Landa, 2003; Landa y Jimenez, 2004), subió bruscamente en el año 2000 y después se mantiene estable hasta la fecha. Los índices de salud, educación y otros indicadores sociales muestran una mejora contínua, incluso durante los años de crisis (Klasen et al., 2005). La estimación de desocupación abierta del INE (Instituto Nacional de Estadística) -una serie con un número de observaciones limitadas- sube destacadamente en 2003, el año de mayor conflicto. Las demás series muestran mucha más variación: por ejemplo, la serie CEDLA (Centro de Análisis de Desarrollo Agrario y Laboral) se duplica entre 2000 y 2003, y hay indicios de que en la ciudad del Alto, el nivel se triplicó durante este periodo (Cuadro 5; $\mathrm{La}$ Prensa, edición extraordinaria 23.12.04; Pulso, número 195, 8 de mayo de 2003). Entre los años 1995 y 2003, El Alto había pasado de ser un barrio pequeño, polvoriento y expuesto al sol y al viento, al lado del aeropuerto internacional, hasta conformar el Soweto de Bolivia, una enorme mezcolanza de aymaras y quechuas, en muchos casos desarraigados de sus lugares de ocupación anterior en la minería o en la agricultura ${ }^{26}$, de las que dependía la economía de toda la mitad occidental del país.

${ }^{25}$ El Gobernador del Banco Central respalda esta idea (página arriba); pero sugiere que la desigualdad, aún más que la caída en los niveles de vida, es el factor que descadenó los motines de 2003.

${ }^{26}$ El Alto de hecho 'se distingue entre todas las ciudades de America Latina por ser una ciudad casi totalmente indígena'. Lazar, 2004, p. 5. 


\section{CUADRO 5}

INDICADORES DE POBREZA Y MALESTAR, 1996-2005

\begin{tabular}{|c|c|c|c|c|c|c|c|c|c|c|}
\hline & 1996 & 1997 & 1998 & 1999 & 2000 & 2001 & 2002 & 2003 & 2004 & 2005 \\
\hline $\begin{array}{l}\text { Bolivia } \\
\text { Línea normal } \\
\text { de pobreza } \\
\text { Pobreza } \\
\text { extrema } \\
\text { 'Desocupación': } \\
\text { INE } \\
\text { CEDLA }^{27}\end{array}$ & & $\begin{array}{l}63.2 \\
36.5\end{array}$ & & $\begin{array}{r}62.3 \\
40.7 \\
4.3\end{array}$ & $\begin{array}{r}65.5 \\
\\
\\
\\
4.8 \\
6.0\end{array}$ & $\begin{array}{r}64.3 \\
\\
\\
5.2\end{array}$ & $\begin{array}{r}64.6 \\
41.3 \\
5.4\end{array}$ & $\begin{array}{r}64.1 \\
\\
6.0 \\
13.5\end{array}$ & 63.6 & \\
\hline $\begin{array}{l}\text { Ciudades } \\
\text { principales } \\
\text { Línea normal } \\
\text { de pobreza } \\
\text { Pobreza } \\
\text { extrema }\end{array}$ & & $\begin{array}{l}50.7 \\
21.3\end{array}$ & & $\begin{array}{l}46.4 \\
20.7\end{array}$ & $\begin{array}{l}52.0 \\
25.7\end{array}$ & $\begin{array}{l}50.5 \\
22.3\end{array}$ & $\begin{array}{l}51.0 \\
23.9\end{array}$ & & & \\
\hline $\begin{array}{l}\text { El Alto } \\
\text { Línea normal } \\
\text { de pobreza } \\
\text { Desocupación }\end{array}$ & & & & & & 66.9 & & & $22.0^{28}$ & \\
\hline $\begin{array}{l}\text { Santa Cruz } \\
\text { Línea normal } \\
\text { de pobreza }\end{array}$ & & & & & & 19.1 & & & & \\
\hline
\end{tabular}

Fuente: Unidad de Análisis de Política Económica (UDAPE); Jimenez y Landa, 2004; Klasen et al., 2005; INE, Anuario Estadistico 2004, tabla 3.06.03.04, página 339; World Bank 2005, tablas 1.1.

Línea 'normal' de pobreza (a precios de 2002) es: Bs 233/mes (zona rural), Bs 321/mes (zona urbana), Bs 327/mes (La Paz). Línea ‘de pobreza extrema’ es: Bs 133/mes (zona rural), Bs 181/mes (El Alto).

Por lo tanto, se puede decir que el reinicio del conflicto social y de la inestabilidad política en Bolivia en 2000 está correlacionado con un aumento en la medida convencional de la pobreza. Sin embargo, la intensificación de este conflicto en 2003 no

${ }^{27}$ Centro de Estudios para el Desarollo Laboral y Agrario, La Paz. Los datos CEDLA se pueden consultar en PULSO (La Paz), nº. 195, 2-8 de mayo de 2005.

${ }^{28}$ ProMujer estimate. Jan 2004. 
se ve ligada a una subida visible de las medidas convencionales de pobreza para Bolivia en su conjunto. Lo que pasó en 2003, es que el incremento de los conflictos dentro de las áreas urbanas y periurbanas del altiplano occidental -la base principal de los aymara- estuvo asociado a una subida del desempleo en esas mismas regiones- y en particular a una subida del desempleo en El Alto, el lugar más politizado del país.

\section{GRÁFICO 3}

\section{POBREZA Y SUBLEVACIONES, 1997-2005 (A) BOLIVIA (B) EL ALTO}

Principales incidentes de violencia política (número de muertes entre paréntesis)

Cambios de gobierno
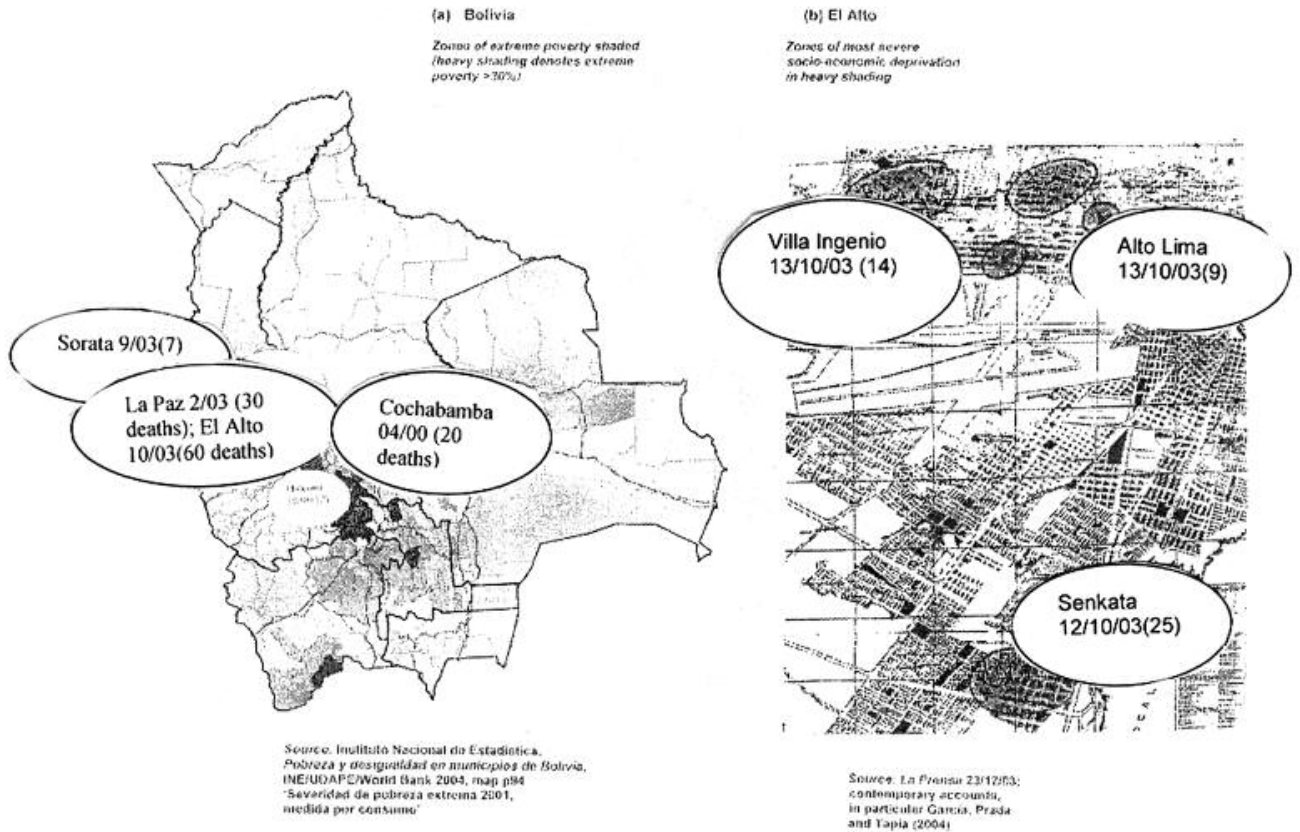

Como se ve en la parte izquierda del gráfico 3, El Alto, y de hecho la mayoría de sitios donde ha habido violencia política a partir de 2000, no están entre las ubicaciones donde se encuentran los niveles más elevados de pobreza en Bolivia, aunque se afirme lo contrario en los medios de comunicacion ${ }^{29}$. Sin embargo, tiene cinco características que, a nuestro juicio, la predisponen hacia niveles elevados de conflicto.

${ }^{29}$ Por ejemplo: La Prensa, 23 de diciembre de 2003, p. 22. 
- En primer lugar, se identifican en El Alto no solamente una tendencia hacia el deterioro del empleo, como vimos anteriormente, sino también en otros indicadores de carencias básicas, como el agua y el alcantarillado.

- En segundo lugar, hay niveles muy altos de la desigualdad personal, incluida la desigualdad intraétnica: una desigualdad que aumenta más rápidamente que los índices convencionales de la pobreza.

- En tercer lugar, la retirada de unos servicios claves para el sustento especialmente de los microempresarios; en particular, se cortaron los préstamos de microfinanzas en todo el país, por la mayoría de agencias, durante la crisis de 1999 (hojas 16/17 arriba; Marconi \& Mosley, 2006). Y El Alto es en Bolivia la región que más depende de las microfinanzas.

- En cuarto lugar, su ubicación estratégica: para paralizar a toda Bolivia y sobre todo a La Paz, lo único que se necesita es bloquear El Alto, donde se encuentran el aeropuerto principal del país (la razón de ser del barrio); las tres carreteras principales que unen La Paz con Perú, Argentina y el este del país, y los oleoductos por los cuales se transfiere el gas natural entre las áreas de producción, La Paz y el exterior.

- En quinto lugar -y quizás más crucial-, El Alto es categóricamente el lugar donde está más politizada la pobreza. El sistema de juntas vecinales, vinculadas por CoJuVe, la Confederación de Juntas Vecinales ${ }^{30}$, facilitó la intercomunicación, de la misma manera que facilitó el acceso a la tecnología moderna. De hecho, las revueltas de octubre de 2003 quizá sean una de las primeras que han organizado por teléfono móvil ${ }^{31}$. Fue también muy importante para la organización del levantamiento que El Alto esté principalmente compuesto por inmigrantes originarios de todas partes de Bolivia, y en particular de mineros y campesinos. Para la confederación campesina la CSUTCB, el Movimiento (campesino) Sin Tierra, y para la confederación obrera la COB, El Alto fue el eje organizacional principal, que sirvió para reforzar y unificar los esfuerzos de las juntas vecinales, proveyéndoles con un marco político de carácter idealista, si bien no totalmente articulado. Un marco doctrinal de naturaleza autárquica y proteccionista, que mezclaba conceptos atávicos de 'devolver los recursos naturales a sus dueños' con ideas sueltas derivadas de la economía temprana del desarrollo, que apoyaba la idea de un proceso de industrialización basado en esos recursos como estrategia de escape de la trampa de la pobreza. La ciudad de El Alto durante los motines recuerda más el ambiente de la Rusia de finales del siglo XIX que cualquier lugar de la época contemporánea:

${ }^{30} \mathrm{La}$ CoJuVe fue financiada principalmente por el MAS de Evo Morales: entrevista, El Alto, septiembre de 2005.

${ }^{31}$ Entrevista, Fernando Romero, 16/9/05. 
'Se habló de hacer de El Alto una ciudad industrial, con empleo y regalías para todos; se discutió la propuesta de hacer de la ciudad un puerto seco, con una grande zona franca... La conclusión, en la mayoría de los eventos, fue que la única oportunidad real de desarrollo para el país, y por consiguiente para los alteños, pasaba por recuperar la propiedad de los hidrocarburos y aprovecharlo para crear empleos y recursos ${ }^{32}$.

De esta forma, durante este periodo se pudo combinar el alto grado de visión y de organización política de El Alto con su habilidad de servir de canal de comunicación de las quejas y agravios de los más pobres. Este papel aumentó de manera destacada las posibilidad de que esas quejas se conviertieran en respuesta violenta.

\section{La selección del instrumento de ajuste y el papel de los donantes}

Cada uno de estos factores - la subida de los partidos étnicos, la desinstitucionalización, y la politización de la pobreza urbana en El Alto - forman el marco que predetermina el espacio de maniobra de la política económica que tiene el gobierno. Ahora pasamos a considerar la manera en que el gobierno aprovechó este margen de maniobra.

El contexto es que bajo la presión de la crisis, del drenaje fiscal causado por la corrupción, y de una serie de decisiones equivocadas de gasto público, el peor de los cuales fue una reforma de las pensiones públicas que según las previsiones del UDAPE costaría 1.100 millones de bolivianos (150 millones de dólares, ó 2\% del PIB) entre 2000 y 2010 (La Prensa, 12/2/03), el gobierno de Sánchez de Lozada se encontró a principios de 2003 (Cuadro 1) con un déficit fiscal que suponía 8.5\% del PIB. Ante la necesidad de cerrar esta brecha, tomó dos decisiones cada una de las cuales sirvieron como detonador del conflicto e hicieron que la trampa política de la pobreza finalmente se cerrara. En Febrero, propuso una extensión del impuesto sobre el ingreso privado hasta cubrir varios sectores de la clase media-baja, incluidas varias categorías de polícias (que se amotinaron). Adicionalmente, en septiembre, como parte de un plan de crecimiento económico, propuso que las exportaciones de gas natural se aumentasen a través de un gasoducto nuevo hacia los puertos de Chile. En parte por la inestabilidad política que causaron, estas decisiones se

${ }^{32}$ Artículo no firmado, Pedagogía de la Sangre: Las lecciones de Octubre, La Prensa, 23 de diciembre de 2003, p. 20. Durante 2003 se publicaron varios artículos en la prensa boliviana que ilustraban cómo se podian convertir los recursos de petróleo y gas natural en productos petroquímicos, plásticos y otros derivados mucho más intensivos en mano de obra que las actividades preexistentes de extracción de hidrocarburos. Ver por ejemplo El Diario, 5 de febrero de 2003, donde se pretende que el valor agregado que se derivaba en 2003 de la exportación de gas natural se podría multiplicar por un factor de entre dos y diez, dependiendo del grado de procesamiento entre 'simple' (generación de electricidad) y 'complejo' (productos petroquímicos). En particular, había posibilidad de exportar a Brasil electricidad generada desde yacimientos de gas ubicados cerca de la frontera brasileña. 
pueden valorar ahora como equivocadas no solamente en un sentido económico, sino también en un sentido fiscal. De hecho cabe preguntarse con qué concepto de racionalidad se adoptaron. La respuesta más obvia es la falta de visión: no se vio la posibilidad de que surgiese un conflicto como consecuencia de esas medidas, y tampoco que dicho conflicto se habría podido evitar con medidas alternativas de política económica. Examinamos cada caso con mayor detalle.

En el caso del aumento del impuesto en la renta personal, en febrero de 2003, parece claro que el FMI fue el autor de la idea de cerrar la brecha fiscal de esta manera, pero dejó abierta la puerta para que el gobierno propusiese medidas alternativas $^{33}$. Cualquier gobierno, consciente de los peligros políticos, habría percibido que, en primer lugar, una subida regresiva ${ }^{34}$ del nivel de impuestos en la parte inferior de la clase media era sumamente peligroso. (Uno de los hallazgos más importantes del estudio OCDE sobre las consecuencias sociales del ajuste [Bourguignon y Morrisson, 1992] era que, de todas las técnicas disponibles para lograr el ajuste fiscal, las alzas en el nivel de impuestos tenían el coste social mayor). El análisis del cuadro 6 indica que existían otras bases fiscales que se habrían podido aprovechar con consecuencias menos regresivas, y con riesgos políticos menos graves.

En segundo lugar, se habría podido cerrar el déficit más rápidamente y con menos injusticia social mediante recortes en el gasto público. En el caso considerado, no solamente no se hizo esto, sino que se aumentó el gasto público durante todo el período de la crisis, con la creación de cuatro nuevos ministerios y nueve viceministerios entre junio de 2002 y febrero de $2003^{35}$. Una estrategia de largo plazo habría podido reducir el coste social de ajuste por medio de un ajuste del patrón de gasto público, adecuándolo a un perfil "pro-pobre". Otra posibilidad habría sido aumentar el salario social de eficiencia -la combinación de políticas que tienen apalancamiento para reducir la inestabilidad política-, y de esta manera aumentan la productividad de todo el gasto público, por analogía con el concepto de 'salario de eficiencia' en la economía del trabajo, donde una subida en el salario privado aumenta la estabilidad y la productividad de la mano de obra ${ }^{36}$. Pero no se adoptó ninguna de estas opciones. La desinstitucionalización previa había contribuido a cerrar los canales por los cuales se habría podido comunicar esas ideas al gobierno.

El detonador para la segunda y más seria ola de violencia política, en octubre de 2003 -el anuncio del gobierno de que intentaba construir un gasoducto a través

${ }^{33}$ Juan Antonio Morales, Gobernador del Banco Central de Bolivia, PULSO, 14-21 de marzo de 2003, página 7 , ofrece esta opinión.

${ }^{34}$ Una estimación de CEDLA (ver el cuadro 5) sugiere que el $61 \%$ de todos los ingresos derivados desde la extensión sugerida de la red de impuestos sobre la renta personal vendría de personas con ingresos de menos de Bs 4000 (\$500) por mes. La Prensa, 12 de febrero de 2003, página 4. Se encuentra un análisis más detallado en Miguel Lora, 'Golpe a la clase media', PULSO, número 183 (7-13 de febrero de 2003), página 11.

${ }^{35}$ La Prensa, 12 de febrero de 2003, p. 6.

${ }^{36}$ Se considera el concepto del 'salario social de eficiencia' en Mosley (2004). 
TABLA 6

IMPACTO DE DOS DECISIONES DE POLÍTICA FISCAL EN 2003, Y LAS ALTERNATIVAS

\begin{tabular}{|c|c|c|c|c|c|c|}
\hline & \multicolumn{3}{|c|}{$\begin{array}{l}\text { Reformas de los impuestos, } \\
\text { febrero de } 2003\end{array}$} & \multicolumn{3}{|c|}{$\begin{array}{l}\text { Exportación de gas natural, } \\
\text { septiembre de } 2003\end{array}$} \\
\hline & $\begin{array}{l}\text { Política } \\
\text { propuesta }\end{array}$ & $\begin{array}{l}\text { Alternativas } \\
\text { factibles } \\
\text { a corto plazo }\end{array}$ & $\begin{array}{l}\text { Alternativas } \\
\text { factibles a } \\
\text { largo plazo }\end{array}$ & $\begin{array}{l}\text { Política } \\
\text { propuesta }\end{array}$ & $\begin{array}{l}\text { Alternativas } \\
\text { factibles } \\
\text { a corto plazo }\end{array}$ & $\begin{array}{l}\text { Alternativas } \\
\text { factibles } \\
\text { a largo plazo }\end{array}$ \\
\hline Descripción & $\begin{array}{l}\text { Extensión } \\
\text { de la red } \\
\text { de impuestos } \\
\text { para cubrir } \\
\text { la clase } \\
\text { media-baja }\end{array}$ & $\begin{array}{l}\text { Reformas } \\
\text { fiscales } \\
\text { de carácter } \\
\text { más progresivo } \\
\text { (ej. impuestos } \\
\text { de aeropuerto, } \\
\text { en ganancias } \\
\text { de las indutrias } \\
\text { privatizadas, } \\
\text { recaudación } \\
\text { de IVA más } \\
\text { eficiente } \\
\text { en la pequeña } \\
\text { industria, } \\
\text { recortes } \\
\text { en el gasto } \\
\text { público) }\end{array}$ & $\begin{array}{l}\text { Aumentos } \\
\text { en los } \\
\text { gastos } \\
\text { públicos } \\
\text { a favor de } \\
\text { los pobres } \\
\text { y en el } \\
\text { 'salario } \\
\text { social de } \\
\text { eficiencia' }\end{array}$ & \begin{tabular}{|l|} 
Construcción \\
de oleoducto \\
a través \\
de Chile, \\
con contratos \\
de exportación
\end{tabular} & $\begin{array}{l}\text { Negociación } \\
\text { de un precio } \\
\text { más alto para } \\
\text { exportaciones } \\
\text { de gas natural }\end{array}$ & $\begin{array}{l}\text { Planes para } \\
\text { industrialización } \\
\text { basados en los } \\
\text { hidrocarburos }\end{array}$ \\
\hline $\begin{array}{l}\text { Impacto } \\
\text { político } \\
\text { visible }\end{array}$ & $\begin{array}{l}\text { Amotinamiento } \\
\text { en La Paz, } \\
\text { febrero } \\
\text { de 2003: } \\
30 \text { muertos }\end{array}$ & $\begin{array}{l}\text { Habría creado } \\
\text { una base } \\
\text { de impuestos } \\
\text { más amplia } \\
\text { (y quizás } \\
\text { menos } \\
\text { vulnerable, } \\
\text { políticamente) }\end{array}$ & $\begin{array}{l}\text { Habría } \\
\text { podido } \\
\text { reducir la } \\
\text { pobreza y } \\
\text { hacer subir } \\
\text { el PIB (ver } \\
\text { la tabla 7) }\end{array}$ & $\begin{array}{l}\text { Amotinamiento } \\
\text { en El Alto, } \\
\text { octubre } \\
\text { de } 2003 \text { : } \\
60 \text { muertos }\end{array}$ & $\begin{array}{l}\text { Podría haber } \\
\text { dado la } \\
\text { impresión de } \\
\text { un gobierno } \\
\text { "activista" } \\
\text { buscando } \\
\text { negociar... }\end{array}$ & \\
\hline $\begin{array}{l}\text { Impacto } \\
\text { en la } \\
\text { desigualdad }\end{array}$ & $\begin{array}{l}\text { Negativa: } \\
\text { la extensión } \\
\text { de la red fiscal } \\
\text { era solamente } \\
\text { para grupos } \\
\text { de bajo ingreso }\end{array}$ & & & $\begin{array}{l}\text { Ningún } \\
\text { impacto } \\
\text { directo, pero } \\
\text { iluminó las } \\
\text { desigualdades } \\
\text { preexistentes }\end{array}$ & $\begin{array}{l}\text { Probablemente } \\
\text { neutral }\end{array}$ & $\begin{array}{l}\text { Probablemente } \\
\text { más intensivo } \\
\text { en mano } \\
\text { de obra que } \\
\text { la industria de } \\
\text { hidrocarburos; } \\
\text { por eso, habría } \\
\text { podido crear } \\
\text { empleo }\end{array}$ \\
\hline
\end{tabular}


de Chile- es en cierto sentido más sorprendente: porque a diferencia del alza de impuestos, en este caso no se incidió directamente en el bienestar de ningún grupo social. Sin embargo, el contexto de privatización del sector de los hidrocarburos, y de diversas industrias estatales ${ }^{37}$, había dejado una herencia de amargura por motivos ya comentados: tuvo un rendimiento muy pequeño para Bolivia al ser controlado por el capital internacional (de hecho muchas firmas no pagaban sus impuestos). En particular, el proceso dio pocos beneficios a la parte occidental y pobre del país.

La amargura fue aún mayor dado que Gonzalo Sánchez de Lozada se había enriquecido por medio de la privatización de la industria minera; y también a causa de un agravio ancestral, cuyo origen se remonta a 1879, contra Chile, por donde debía pasar el gasoducto. En el contexto todavía recesivo de mediados de 2003, el gobierno necesitaba urgentemente incrementar los ingresos fiscales y de exportación, y una vez más no se dio cuenta de la peligrosidad de la vía que había adoptado. Los motines de octubre de 2003 se pueden interpretar como una protesta contra la desigualdad, aumentada por el complejo de políticas pro-capital extranjero que la oposición radical llamaba entreguismo. Una opción política que, según se comentó, no era la única opción disponible para el gobierno: la misma meta se habría podido alcanzar a través de medidas menos regresivas, por ejemplo impuestos sobre las ganancias de las industrias petroleras; medidas para incrementar el salario social de eficiencia; medidas para aumentar el valor agregado de la exportación del gas natural no procesado; y, quizás más importante, democratización de la toma de decisiones sobre los recursos petroleros del país. La primera y segunda de estas medidas, de hecho, fueron implementados por el gobierno Mesa entre 2004 y 2005, y durante 2006 el nuevo gobierno Morales había planificado y tratado de implementar la tercera y la cuarta.

Era de esperar que los donantes -al menos el grupo de cuatro que monopolizaba la asistencia en el campo presupuestario y de política macroeconómica que recibe el gobierno boliviano ${ }^{38}$ - habrían considerado advertir al gobierno Sánchez de Lozada sobre los peligros asociados a su política de ajuste, pero no lo hicieron. Incluso, el presidente de uno de ellos apareció en la televisión nacional para defender que el umbral de las rentas gravables se extendiese hacia abajo en la renta personal el 11 de febrero, horas antes de que primero los policías y, después, toda La Paz se amotinaran contra la injusticia (Lazarte Rojas, 2005: 18). El representante del Banco Mundial sostuvo, de manera poco fundada, que no veía que la política fiscal y otras cuestiones de corto plazo fuesen responsabilidad del Banco, sino más bien del Fondo ${ }^{39}$; y la posición de la CAF en ese tiempo era la de tratar

${ }^{37}$ La 'guerra del agua' de Cochabamba en abril de 2000, que inició la ola presente de inestabilidad política, se puede analizar de la misma manera, i.e. como una protesta contra la subida de la desigualdad motivada por una industria privatizada. En Cochabamba ese mes de abril, se triplicó el precio del agua y mucha gente se vió forzada a elegir entre la comida y el agua (McNeish 2005).

${ }^{38}$ El FMI, el Banco Mundial, el BID y la Corporación Andina de Fomento.

${ }^{39}$ Entrevista, Carlos Mollinedo, Banco Mundial, Oficina de La Paz, 14 de septiembre de 2005. 
de acelerar la implementación de proyectos no concluidos, más que la de frenar la velocidad de la reforma fiscal ${ }^{40}$. En este caso no hubo el tradicional problema de coordinación entre los donantes, y entre ellos y el gobierno Sánchez de Lozada: las políticas de éste último fueron aprobadas y respaldadas por este grupo de donantes. Éste fue precisamente el problema: no tanto la falta de coordinación entre los donantes, sino la excesiva coincidencia entre ellos. Si solamente uno de ellos hubiera advertido al presidente de los peligros de su política económica, es posible que se hubiera podido frenar la dinámica de factores propios de la trampa de la pobreza ${ }^{41}$.

\section{Modelización de la trampa política de la pobreza}

Por lo tanto, los cuatro factores que analizamos - la desinstitucionalización, los cambios en el funcionamiento del sistema de partidos, el factor 'El Alto', y el hecho que el gobierno no aprovechó su capacidad de maniobra - convirtieron un shock externo en una trampa política de la pobreza. Ahora tratamos de comprender este proceso con un modelo. El gráfico 4 contiene la lógica de relaciones supuestas, que está directamente transcrito desde la parte derecha del gráfico 1.

Los resultados de la estimación de este sistema de ecuaciones simultáneas se recogen en la tabla 7. El fundamento de este sistema se explica a continuación:

- Violencia política (relación (1)). Como se señaló, la violencia en Bolivia se agravó por la desinstitucionalización, por la desconfianza en las instituciones políticas y por políticas equivocadas. El factor 'El Alto' se incorpora a través de valores para las variables independientes definidas para El Alto solamente. Esta explicación de la violencia causada por las políticas de estabilización utiliza una fundamentación de la violencia en términos de costes y beneficios parecido a la explicación que se ha usado en conflictos más amplios como guerras civiles (Collier and Hoeffler, 1996, Fielding, 2004), pero lo desarrolla con una consideración de factores que no solamente reducen el coste o incrementan el beneficio que se obtiene de la violencia (por ejemplo, desigualdad o nivel de organización en El Alto), sino que aumentan la visibilidad de los agravios (como por ejemplo la metamorfosis de los partidos políticos ${ }^{42}$ ).

${ }^{40}$ Entrevista, Oscar Bonifaz Paz, CAF, La Paz, 22 de septiembre de 2005.

${ }^{41}$ La CAF, de forma tardía, está desembolsando un Préstamo de Distensión Social, que consiste de gastos de tipo 'Fondo Social de Emergencia', enfocados a regiones de alta tensión política como las que aparecen en Negro en el gráfico 3. La idea es alabable; pero la prevención habría sido aún mejor que la cura.

${ }^{42}$ Esta relación se ha modelizado para Bolivia por Escalante y Yanez (2005); sin embargo, estos autores no presentan datos sobre el conflicto. 


\section{GRÁFICO 4 \\ LA ' TRAMPA POLÍTICA DE LA POBREZA': VERSIÓN ESTIMADA}

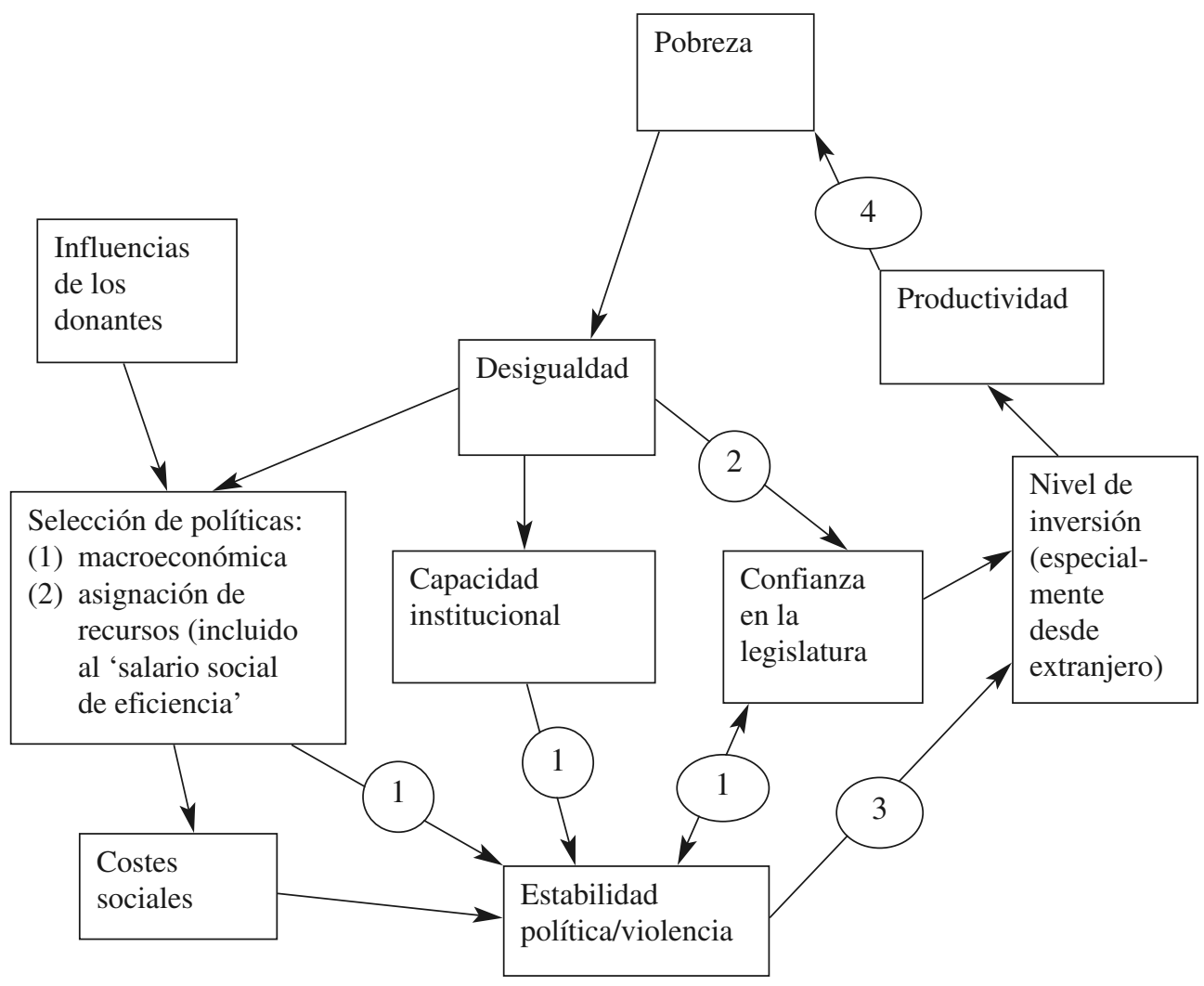

- Confianza en el gobierno (relación (2)). Se puede esperar, como en los países industrializados ${ }^{43}$, que la confianza en el gobierno seguirá un 'ciclo electoral' en el que cada nuevo gobierno gana un "depósito" de popularidad electoral que gradualmente gasta, pero normalmente vuelve a obtener apoyo en los meses previos a la elección. También se espera que la popularidad refleje el nivel de desempeño económico del gobierno; en la literatura sobre países industrializados, esto se representa por los niveles de desempleo y de consumo

${ }^{43}$ En los países industrializados, la literatura substancial trata de estimar 'funciones de popularidad', utilizando datos extraídos de sondeos de opinión popular como variable dependiente. Ver Kramer (1970), Goodhart y Bhansali (1971) y Mosley (1978). Las estimaciones presentadas en el cuadro 7 constituyen uno de los primeros intentos de construir una función de popularidad para un país en desarrollo. 


\section{TABLA 7}

\section{MODELO 'TRAMPA POLÍTICA DE POBREZA': ANÁLISIS DE REGRESIONES}

Regression coefficients on independent variables:

\begin{tabular}{|c|c|c|c|c|c|c|}
\hline \multirow{2}{*}{$\begin{array}{l}\text { Variables } \\
\text { Variables } \\
\text { Independientes }\end{array}$} & \multirow{2}{*}{\multicolumn{2}{|c|}{$\begin{array}{l}\text { Violencia política } \\
\text { (vínculo 1) }\end{array}$}} & \multirow{2}{*}{$\begin{array}{l}\text { Confianza } \\
\text { en el } \\
\text { gobierno } \\
\text { (vínculo 2) }\end{array}$} & \multicolumn{2}{|c|}{$\begin{array}{l}\text { Tasa de inversión } \\
\text { (vínculo 3) }\end{array}$} & \multirow{2}{*}{$\begin{array}{l}\text { Coeficiente } \\
\text { Gini de } \\
\text { desigualdad } \\
\text { (vínculo 4) }\end{array}$} \\
\hline & & & & $\begin{array}{l}\text { Desde } \\
\text { Exterior }\end{array}$ & Total & \\
\hline Constante & $\begin{array}{l}-400.0 * * \\
(4.49)\end{array}$ & $\begin{array}{l}-431.3^{* * *} \\
(10.34)\end{array}$ & $\begin{array}{l}143.9^{* *} \\
(2.81)\end{array}$ & $\begin{array}{l}8.01 \\
(0.45)\end{array}$ & $\begin{array}{l}17.7 * * \\
(58.7)\end{array}$ & $\begin{array}{l}34.4^{* *} \\
(4.49)\end{array}$ \\
\hline Nuevo gobierno & & & $\begin{array}{l}17.3^{* *} \\
(3.62)\end{array}$ & & & \\
\hline $\begin{array}{l}\text { Desocupación (datos INE), } \\
\text { áreas urbanas solamente }\end{array}$ & $\begin{array}{l}3.86 \\
(1.19)\end{array}$ & & $\begin{array}{l}15.08^{* *} \\
(2.67)\end{array}$ & & & \\
\hline $\begin{array}{l}\text { Desocupación (datos CEDLA), } \\
\text { áreas urbanas solamente }\end{array}$ & & $\begin{array}{l}0.53 \\
(0.50)\end{array}$ & & & & \\
\hline $\begin{array}{l}\text { Coeficiente Gini } \\
\text { de desigualdad }\end{array}$ & $\begin{array}{l}6.11^{* *} \\
(3.76)\end{array}$ & $\begin{array}{l}5.78^{* *} \\
(7.55)\end{array}$ & & & & \\
\hline \multicolumn{7}{|l|}{ Confianza en el gobierno } \\
\hline $\begin{array}{l}\text { Indicador de militancia } \\
\text { política }\end{array}$ & $\begin{array}{l}-0.032 \\
(0.11)\end{array}$ & $\begin{array}{l}0.16^{*} \\
(2.04)\end{array}$ & & $\begin{array}{l}-0.14^{* *} \\
(4.75)\end{array}$ & $\begin{array}{l}-0.11^{* *} \\
(7.37)\end{array}$ & \\
\hline $\begin{array}{l}\text { Indicador de violencia } \\
\text { política }\end{array}$ & & & & $\begin{array}{l}-0.071 \\
(0.07)\end{array}$ & $\begin{array}{l}-0.081^{* *} \\
(4.06)\end{array}$ & \\
\hline $\begin{array}{l}\text { Crecimiento de consumo } \\
\text { per cápita }\end{array}$ & & & $\begin{array}{l}115.2^{*} \\
(1.95)\end{array}$ & & & \\
\hline $\begin{array}{l}\text { Tasa de inversión } \\
\text { (\% PIB) }\end{array}$ & & & & & & $\begin{array}{l}-0.39 * * \\
(3.69)\end{array}$ \\
\hline \multicolumn{7}{|l|}{ Gastos públicos 'pro-pobres' } \\
\hline \multicolumn{7}{|l|}{$\begin{array}{l}\text { Índice de la corrupción (índice } \\
\text { Transparency International) }\end{array}$} \\
\hline Línea normal de pobreza & $\begin{array}{l}1.50 \\
(0.81)\end{array}$ & $\begin{array}{l}1.01 \\
(1.76)\end{array}$ & & $\begin{array}{l}0.048 \\
(0.17)\end{array}$ & & $\begin{array}{l}0.55^{* *} \\
(4.54)\end{array}$ \\
\hline Número de observaciones & 28 & 28 & 60 & 28 & 28 & 28 \\
\hline $\mathrm{R}^{2}$ & 0.91 & 0.92 & 0.59 & 0.68 & 0.76 & 0.55 \\
\hline
\end{tabular}

Nota: Estimados 'three stage least squares' (3SLS): datos para cada periodo de tres meses desde principios de 1999 hasta finales de 2005, así $\mathrm{n}=28$.

Fuentes y definiciones:

Indicador de violencia política: muertos mensuales en manifestaciones, huelgas y motines, índice calculado desde Fuentes originales, ver la tabla 3 .

Línea normal de pobreza, coeficiente Gini de desigualdad, tasa de desocupación INE, inversión total, inversión desde extranjero: Instituto Nacional de Estadística (INE), Estadísticas socio-económicas 2004, actualizados hasta mediados de 2006 desde el sitio web INE (www. ine.gov.bo).

Tasa de desempleo CEDLA: Centro de Estudios para el Desarrollo Laboral y Agrario, La Paz.

Confianza en el gobierno: Apoyo Opinión y Mercado, Informe de Opinión, número de agosto 2005 actualizado hasta el presente. Indicador de militancia política: proporción de escaños ocupados por miembros de partidos comprometidos a la acción extraparlamentaria (MAS y MIP). 
promedio per-capita. Pero en el caso boliviano, otros factores han afectado el nivel de confianza en el gobierno, notablemente el nivel de violencia política. Así, en nuestra estimación del nivel de apoyo al gobierno (vínculo (2)) en Bolivia, conservamos 'meses pasados a partir de la última elección', el nivel de desempleo, y el cambio en el consumo personal de la literatura analítica sobre resultados electorales; y añadimos para nuestra estimación de la violencia política (muertos mensuales en motines y manifestaciones) el análisis de regresiones.

- Violencia, inversión y pobreza (relación (3)). Los últimos vínculos en esta parte de la trampa de la pobreza son las relaciones que existen entre inestabilidad política e inversión. Podemos suponer que un nivel mayor de inestabilidad política reducirá el nivel de inversión doméstica, y especialmente extranjera (como se argumenta en Alesina y Perotti(1996)), y que una reducción en el nivel de inversión, completando el círculo vicioso, se asociará posteriormente con un nivel más alto de pobreza.

Los resultados de las regresiones confirman todos los vínculos del 'círculo vicioso de la pobreza', pero con algunas sorpresas. Los primeros dos vínculos se ven en el Gráfico 5: nuestro indicador de violencia política responde en particular al nivel del coeficiente Gini de desigualdad (que refleja que los instintos del Gobernador del Banco Central estaban fundamentados); también está relacionado de manera significativa con el nivel de desempleo urbano y el nivel de incidencia de la pobreza. Como también se recoge en el gráfico 5, la confianza en el gobierno (medida por la empresa boliviana Apoyo Opinión y Mercado) sube al inicio de cada período electoral y responde de manera negativa al nivel de violencia política (como en los países industriales) pero también cae a medida que el nivel de violencia política sube. La inversión (y en particular el nivel de inversión desde el exterior) también responde al nivel de violencia y de militancia política: cae con rapidez en períodos como 2000 y 2003 cuando la inestabilidad política es alta y sube cuando vuelve la calma, como se ve también en los análisis de Alesina y Perotti (1996). Finalmente, para completar el círculo vicioso, el coeficiente Gini de desigualdad responde negativamente a una caída de la inversión extranjera y a un aumento de la desigualdad.

\section{Comparaciones internacionales}

Para comprender mejor la cuestión de como cayó Bolivia en una trampa política de la pobreza, retomamos ahora la comparación entre Bolivia y otros países afectados por la crisis global. En la tabla 8, comparamos los valores de las variables claves que determinan la probabilidad de una salida de la crisis -capacidad institutional, desigualdad, y una variedad de indicadores de la progresividad de la política económica- entre Bolivia y los demás países golpeados por la crisis que están representados en la tabla 1. En relación a los factores que predisponen hacia la vulnerabilidad po- 


\section{GRÁFICO 5(a) \\ BOLIVIA 1999-05: VIOLENCIA POLÍTICA, DESEMPLEO Y POBREZA}

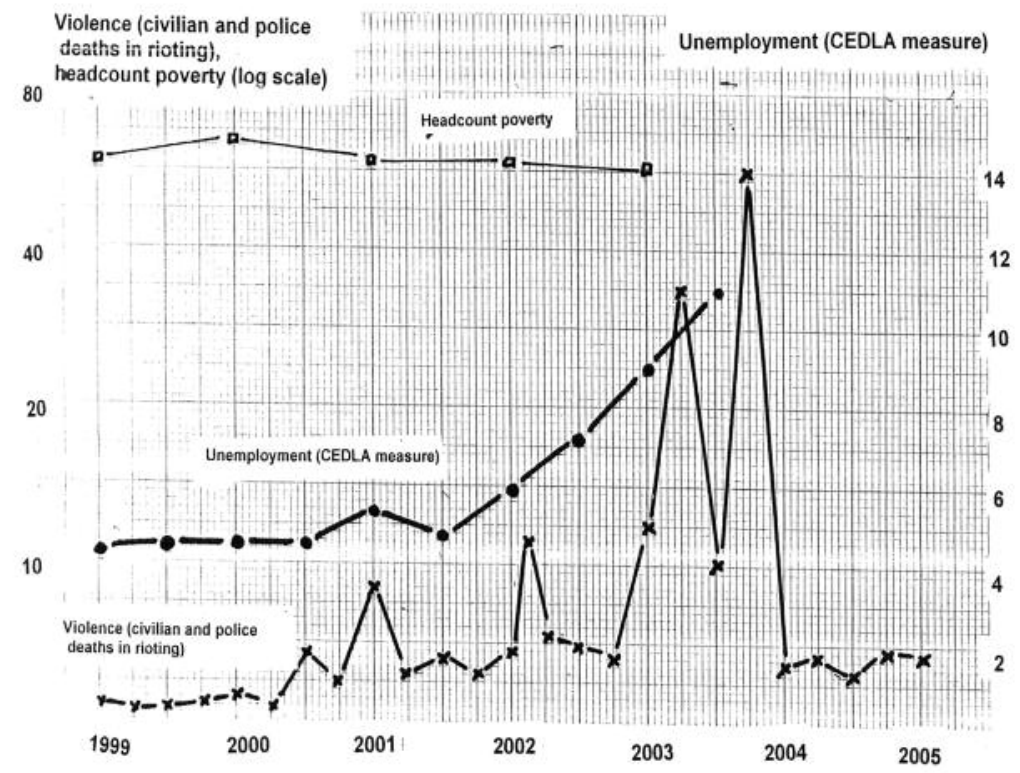

GRÁFICO 5(b)

BOLIVIA 2002-05: CONFIANZA EN EL GOBIERNO Y POSIBLES DETERMINANTES

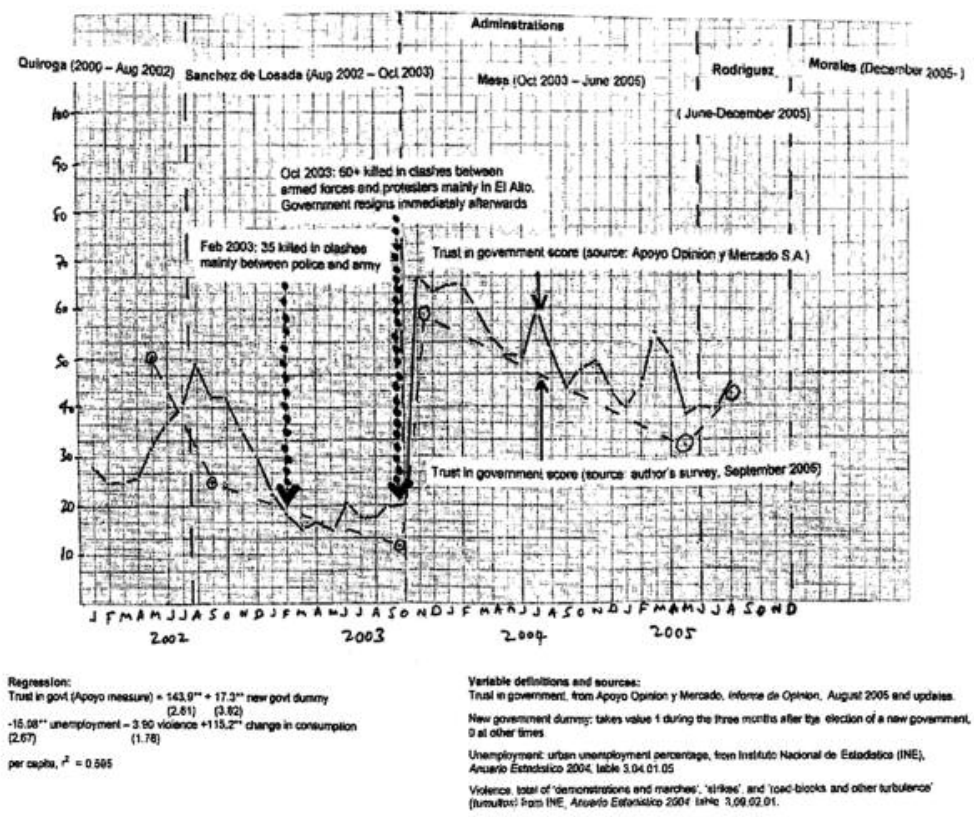


TABLA 8

PAÍSES EN CRISIS: INDICADORES DE VULNERABILIDAD

\begin{tabular}{|c|c|c|c|c|c|c|}
\hline & \multicolumn{2}{|c|}{ Condiciones iniciales } & \multicolumn{4}{|c|}{ Políticas implementadas (ver la tabla 7) } \\
\hline & $\begin{array}{l}\text { (1) Coeficiente } \\
\text { Gini de } \\
\text { desigualdad }\end{array}$ & $\begin{array}{l}\text { (2) Capacidad } \\
\text { institucional: }\end{array}$ & $\begin{array}{l}\text { (3) Impacto } \\
\text { del ajuste } \\
\text { en los pobres }\end{array}$ & $\begin{array}{l}\text { (4) Eleme } \\
\text { 'salario so } \\
\text { de eficienc }\end{array}$ & $\begin{array}{l}\text { tos del } \\
\text { ial } \\
\text { a' }\end{array}$ & $\begin{array}{l}\text { (5) Número } \\
\text { de controles } \\
\text { sobre flujos }\end{array}$ \\
\hline & & $\begin{array}{l}\text { Índice Banco } \\
\text { Mundial } \\
\text { 'voice and } \\
\text { accountability', } \\
2000-01\end{array}$ & $\begin{array}{l}\text { Cambio (\%) } \\
\text { de la tasa de } \\
\text { cambio real } \\
(1995=100) / \\
\text { cambio }(\%) \\
\text { en el valor } \\
\text { medio de } \\
\text { impuestos }\end{array}$ & $\begin{array}{l}\text { (a) Valor } \\
\text { promedio } \\
\text { del índice } \\
\text { 'gastos } \\
\text { a favor } \\
\text { de los } \\
\text { pobres' } \\
\text { (PPE) }\end{array}$ & $\begin{array}{l}\text { (b) Salud } \\
\text { y } \\
\text { educación } \\
\text { como } \\
\text { porcentaje } \\
\text { del PIB }\end{array}$ & \\
\hline Indonesia & 32 & -0.40 & 163.0 & 0.44 & 7.7 & 12 \\
\hline Malaisia & 44 & -0.13 & 56.7 & 0.52 & 6.1 & 6 \\
\hline Tailandia & 43 & 0.37 & 40.4 & 0.56 & 6.9 & 12.5 \\
\hline Turquia & & -0.54 & -23.3 & & 13.6 & 9.6 \\
\hline Rusia & & -0.34 & 37.7 & 0.36 & 4.6 & 12.1 \\
\hline Brasil & 63 & 0.52 & 134.2 & & 8.5 & 13.1 \\
\hline Argentina & 58 & 0.57 & 160.0 & & 12.2 & 7.8 \\
\hline Bolivia & 59 & 0.27 & -10.3 & 0.52 & 7.9 & 3.6 \\
\hline
\end{tabular}

\section{Fuentes:}

Coeficiente Gini de desigualdad (col. 1) : Banco Mundial, World Development Indicators, CD-ROM.

Indicador Banco Mundial de capacidad institucional (col. 2): sitio Web Banco Mundial, www.worldbank.org./wbi/governance/govdata2002/(ver también Kaufmann et al. (2003)).

Impacto del ajuste en los pobres (col. 3): medida como aumento (\%) de la tasa de cambio real $(1995=100)$ dividida por el cambio (\%) en el valor medio de impuestos; un aumento (caída) en este índice significa un alivio (agravamiento) del impacto del ajuste en los pobres; fuente original para ambos es IMF, International Financial Statistics.

'Gastos a favor de los pobres' (PPE) y porcentaje de gastos en educación y salud en el PIB: IMF Government Statistics Yearbook (para más detalle de los métodos usados para calcular el índice PPE, ver Mosley, Hudson y Verschoor (2004)).

lítica, Bolivia, en 2003, tenía niveles del coeficiente Gini de desigualdad más altos, con excepción de Brasil (columna 1 de la tabla), niveles de capacidad institucional menores, con excepción de Malasia (columna 2), y niveles de intervención para protegerse frente a shocks externos (columna 6). Así se puede fácilmente explicar el hecho de que Bolivia permanezca más tiempo en el círculo vicioso de la pobreza que los demás países en términos de estos factores de riesgo. (Hay que observar, sin 
embargo, que en términos de otros factores de riesgo, como la asignación del gasto público a sectores en favor de los pobres como salud y educación, Bolivia está por debajo en la escala de riesgo).

Sin embargo, otros factores de riesgo que explican la persistencia de unos países dentro de la trampa de pobreza se deben explicar más bien en términos de decisiones discrecionales, que en términos de condiciones iniciales. En particular, encontramos más evidencia de que las elecciones de política económica hechas por el gobierno boliviano fueron sesgadas contra grupos de alta sensibilidad política, frecuentemente de bajo ingreso, aunque los indicadores no estén todos orientados en la misma dirección.

En primer lugar, los cambios en los impuestos, como ya vimos, estaban deliberadamente sesgados contra la clase media-baja, en una manera que provocó directamente la explosión de enero de 2003. En segundo lugar, el diseño de la política económica externa también estuvo falto de imaginación en su provisión de medidas para comprar la lealtad de los políticamente excluidos. Un indicador que apoya esta idea es que Bolivia, casi de forma exclusiva en el cono sur de América Latina, no impuso controles ni en los flujos de entrada de capital en el país, ni tampoco en las salidas de fondos (columna 5 del cuadro). Una medida que en Chile, Argentina y Malasia jugó un papel importante en la protección del empleo, y en ofrecer la impresión de que el gobierno controlaba (en vez de ser dominado) los movimientos internacionales de capital. Otro ejemplo es la relación entre la variación en el tipo de cambio real y el aumento en los impuestos, que es un indicador que aproxima la progresividad de la política económica (Bourguignon y Morrisson, 1992) y es relativamente baja en Bolivia.

Sin embargo, hay que reconocer que respecto a algunos otros indicadores, sobre todo la salud y a la educación, Bolivia estaba en una línea de mejora en relación a otros países ${ }^{44}$. Esto puede ser una razón que explique que los donantes, cuya ayuda se concentraba en estas áreas, se viesen soprendidos por los acontecimientos de 2003. Así algunos componentes del 'salario social de eficiencia' se habían mejorado en toda Bolivia, y explícitamente en áreas donde estaba concentrada la pobreza aymara y quechua, sin embargo, no se había logrado una mejora del salario social de eficiencia en El Alto, el epicentro del descontento.

Un factor de agravamiento de la situación era que las medidas que tuvieron mucho éxito en Bolivia, en los noventa, particularmente las microfinanzas, a diferencia de otros países afectados por la crisis global (y notablemente Indonesia) experimentaron recortes en su provisión por motivo sobre todo de la debilidad institucional ${ }^{45}$.

${ }^{44}$ Klasen et al. (2005).

${ }^{45}$ En particular las instituciones de microfinanzas experimentaron subidas en su tasas de impago debido a que proporcionaron durante el boom sumas crecientes de crédito al consumo en cantidades que los clientes, una vez llegada la recesión, no pudieron repagar (Rhyne, 2002). Más aún, en vez de insistir en que se reembolsen los créditos, algunas instituciones de microfinanzas pidieron, y el gobierno Banzer otorgó, liquidaciones parciales de las deudas morosas, minando así la disciplina financiera del sector microfinanciero. 
Así, otros países afectados por la crisis global -como Indonesia- no experimentaron ningún recorte y pudieron utilizar las microfinanzas como herramienta anticíclica (Marconi y Mosley, 2006) ${ }^{46}$. Una segunda tendencia, aún más severa, fue que el apoyo de las agencias financieras internacionales, que tenían mucho más que perder en economías grandes como Rusia, Turquía, Argentina y Brasil, resultó mucho menos generosa en el caso de Bolivia (una economía relativamente pequeña). Se financió al primer grupo de países con el nivel de ayuda que se necesitaba para prevenir que la economía cayese en una espiral descendente; pero no se creyó necesario utilizar ese enfoque en Bolivia, donde ningún donante advirtió los peligros que una deflación demasiado importante podría tener en el país a la hora de hacer frente al crédito.

\section{Conclusión}

La vuelta de Bolivia a la inestabilidad económica y política a partir del año 2000 ha sido interpretado por muchos, sobre todo en Bolivia, como un resultado predestinado; para algunos analistas, lo que pasó entre 1999 y 2005 representa la consecuencia lógica de un proceso que se inició en 1879 (Molina, 2005). Estos analistas identifican la predisposición del país hacia la acción popular y hacia la corrupción de las élites como un 'efecto fijo' que hace inevitable la inestabilidad, y encierra a la mayoría dentro de la trampa de la pobreza.

En este trabajo hemos mantenido que ésta aparente predestinación es exagerada. Hemos visto que las condiciones iniciales con las que Bolivia operaba durante el proceso de ajuste estructural de los noventa -en el sentido de desigualdades sobre todo interétnicas, agravadas por una concentración geográfica de militancia política- no constituía una buena base para poder afrontar la nueva crisis económica de principios de los 2000. También vimos cómo las variables características de nuestra 'trampa política de la pobreza' -la desinstitucionalización y la decadente legitimidad del sistema de partidos dominado por las élites- aumentaron la vulnerabilidad del gobierno Sánchez de Lozada y, en menor medida de sus sucesores, mientras se afrontaba esa crisis. Cada uno de estos factores es importante también para entender la persistencia de otras crisis económicas, por ejemplo Turquía e Indonesia a finales de los 1990 y a principios de los 2000.

Sin embargo, varios elementos de este proceso han sido específicos al caso de Bolivia, incluido el alto grado de politización de una ciudad muy atípica y el campo de visión muy restringido del gobierno en la crisis de 2003. Una visión restringida a la elección de personas con quienes el gobierno estaba dispuesto a negociar, en la elección de herramientas de política económica que estaba dispuesto a utilizar, y

${ }^{46}$ Esta tendencia no fue universal: algunas instituciones, especialmente las ONGs de microfinanzas con un modelo de banco communal, resistieron al retroceso. Ahora (septiembre de 2006) la tendencia es de nuevo ascendente, y el sector de microfinanzas crece a una tasa de $25 \%$ por año (entrevista, Fernando Romero, 16 de septiembre de 2005). 
finalmente en la elección de las medidas de comunicación que utilizó para demostrar las ganas de compensar por las pérdidas que causaba. La dependencia que Bolivia tiene de los donantes de ayuda y de sus consejos fueron, en nuestra opinión, un pasivo y no un activo en el sentido de que no ayudó al gobierno a percibir el margen de maniobra que tenía. Así, la salida de Bolivia de la trampa de pobreza, durante el período bajo examen, fue impedido, en parte por las malas condiciones iniciales, pero sobre todo por las malas políticas y la falta de visión.

Con este artículo ha quedado ilustrada esta tesis, principalmente en relación a las decisiones adoptadas en materia de impuestos y de política petrolera durante el 'año cumbre' de 2003, pero hay muchos casos de menor visibilidad política (política de pensiones, asignación de gastos públicos, controles sobre flujos de capital) que también sirvieron para entender la actuación del gobierno. Entre 2000 y 2005, ésta quedó bloqueada con la consiguiente pérdida de confianza y un incremento en la espiral de la pobreza. Desde 1999, el PIB per capita cayó un 15 por ciento, aunque el país actualmente pase por un boom en el sector petrolífero.

¿Cuáles son las opciones principales para escapar de la trampa de la pobreza? Como lo ilustra el modelo del gráfico 3, lo esencial consiste en influir de manera sostenible sobre las variables claves, como la inversión y el segmento bajo del mercado de trabajo; y nuestro modelo no hace más que poner énfasis sobre la importancia de las variables políticas e institucionales en que estas variables inciden. Algunos analistas, incluso el gobierno actual, han visto la solución principalmente en términos de un desplazamiento hacia instrumentos del tipo del 'post-consenso de Washington'. 'Éste (o sea, octubre de 2003) es el momento en que el modelo neoliberal se agotó', declaró un miembro de la Cámara de Diputados a La Prensa (23 de diciembre de 2003), y el programa del gobierno actual muestra una creencia en que las medidas proteccionistas pueden aumentar la justicia distributiva percibida por el público y, a través de este canal, la estructura de la demanda ${ }^{47}$, la inversión, y la confianza de la clase media. El manifiesto del gobierno MAS aplica este razonamiento con un fervor particular al caso de la industrialización basada en el sector de hidrocarburos. Otros analistas, que también incluyen al gobierno MAS, han visto la solución en términos de reinstitucionalización, en especial, a través de una Asamblea Constituyente, y aquí también hay muchos paralelismos con el enfoque del gobierno Kirchner en Argentina. Finalmente, los canales de comunicación son importantes, tanto para los donantes (que en el momento crucial, no transmitieron las advertencias necesarias al gobierno Sánchez de Lozada) como para los gobiernos de Bolivia -que en otros momentos críticos como en 2003 y 2005, no percibieron la erosión de la confianza de la clase media. La estructura de dichos canales de comunicación, conjuntamente con la amplitud del campo de visión del gobierno y los incentivos que ofrecen sus instituciones, parecen claves para determinar el carácter acumulativo o transitorio de la crisis.

${ }^{47}$ En su énfasis en el lazo entre distribución de ingresos y la estructura de la demanda el manifiesto MAS recuerda uno de los más importantes argumentos modernos a favor de un programa de desarrollo equilibrado industrial o 'Big Push' (Murphy, Shleifer y Vishny, 1989). 
¿Qué esperanza hay de que el gobierno 'neodesarrollista' de Morales, que a partir de principios de 2006 ha implementado una estrategia alternativa para escapar de la trampa de la pobreza, pueda finalmente "revertir" la espiral? La respuesta requiere considerar los cuatro factores específicos a Bolivia que, según nuestro análisis, "mantuvieron cerrada" la trampa de la pobreza. Con referencia a dos de estos factores, se puede ofrecer una respuesta bastante positiva: el antiguo sistema de partidos, y al parecer la mayor parte de la corrupción que lo acompañaba, parece haber desaparecido, y el 'factor el Alto', que impulsó a Morales hacia el poder, ha continuado respaldando su presidencia; el nivel de violencia política ha disminuido en 2006, aunque hay informes recientes desde Sucre y desde Huanuni que señalan que se ha utilizado la táctica clásica alteña de promover una huelga de hambre para forzar aumentos en el gasto público. ${ }^{48}$

Sin embargo, con referencia a los dos otros factores, la desinstitucionalización y la elección de políticas económicas, el juicio es más provisional. Como era de esperar, ese hombre que en la oposición una vez describió el capitalismo como 'el peor enemigo de la humanidad" ${ }^{49}$, no ha tratado de destruirlo, una vez que ha llegado a la presidencia. Y algunas de las formas en que esto se ha manifestado (por ejemplo, el hecho de que no haya moratoria en las deudas de las microfinanzas) indudablemente han beneficiado al desarrollo institucional, y ha permitido al Banco Central ser conservador en la gestión de la oferta de dinero. ${ }^{50}$ La Asamblea Constituyente, después de una huelga de hambre en 2009, finalmente ratificó los derechos legales de las minorías étnicas; y en mayo de 2006, el parlamento aprobó la reforma del sector de hidrocarburos estableciendo un impuesto directo de hasta el $80 \%$ del valor de las exportaciones, cuyo rendimiento se dedicará como suplemento (Renta Dignidad) a la pensión estatal, de acuerdo con el modelo argentino. 'Finalmente' declaro el Ministro para Hidrocarburos, Andrés Solis Rada el 26 de junio de 2006 en el marco de un nuevo acuerdo para vender gas a Argentina a un precio más elevado, "hay una idea que puede unir a los sectores sociales dispersos" ${ }^{" 51}$; pero no es obvio que esta estrategia funcione. Por su parte, los donantes a pesar de recibir algunos consejos poco razonables inmediatamente después de la ascensión de Morales $^{52}$, no han retirado su apoyo, tampoco han vuelto a dar consejos fiscales cuya implementación ayudó a destrozar a Sánchez de Lozada; pero la prueba llegará cuando el precio del petróleo, que

48 'Problemas para Evo: protesta cívica y huelga de hambre en Sucre', El Mundo, 1 de septiembre de 2006, http://www. clarin.com/diario/2006/09/01/el mundo/i-02301.

49 Andrew Mueller, 'The cuddly crusader' [perfil de Evo Morales], informe en Independent on Sunday, 7 de mayo de 2006.

${ }^{50}$ El manifiesto para la nueva política económica del gobierno Morales (Bolivia, 2006) enfatiza que la política en relación a las multinacionales consiste en 'convivencia' (Bolivia, 2006, p. 17) y no expropiación y se espera la colaboración con ellos especialmente en la industrialización basada en el sector de hidrocarburos (Bolivia, 2006, pp. 17 y 27).

51 'Reversing neoliberalism: an interview with Bolivia’s new Energy Minister', worldpress.org/article.id=2372. En el acuerdo mencionado, el precio de exportación del gas natural aumentó desde \$3.25 millones de British Thermal Units ( BTU) hasta \$5 millones de BTU.

${ }^{52}$ Por ejemplo Michael Rada, 'The end of Bolivia?', 21 de diciembre de 2005, www.fpri.org. 
actualmente funciona como un freno que impide que la situación fiscal o distributiva empeore, comience otra vez a bajar.

Por tanto, nuestra tesis principal es que algunos de los elementos que perpetúan y profundizan la pobreza son políticos, y no se pueden situar en el comportamiento individual o en instituciones ineficientes. Hemos identificado y estimado cuatro elementos en la trampa política de la pobreza, algunos de los cuales se pueden ver como específicos de Bolivia y otros son más generales. Aunque se ha orientado el contenido principal hacia los factores específicos del caso boliviano, nuestro análisis también sugiere que algunos de los requerimentos para el ajuste en los países en desarrollo han podido cambiar desde el estudio de la OCDE (Bourguignon y Morrisson, 1992). Primero, porque el ambiente político actual favorece más a los pobres y, segundo, porque los flujos de capital son hoy mucho más móviles. En particular, la opinión de la OCDE de que el ajuste no se debía orientar hacia los más pobres (Haggard, Lafay y Morrisson, 1995) aparece como anticuada. Es más, lo que se necesita, según la evidencia boliviana, no es solamente un ajuste en favor de los pobres, sino también un ajuste orientado hacia los indicadores adecuados de la pobreza y de la desigualdad -en concreto lo que podemos llamar la 'desocupación politizada', como en El Alto. Una dimensión del ajuste en favor de los pobres es una política fiscal "pro-pobre", una lección que el gobierno Sánchez de Lozada no aprendió. Otro aspecto es el desarrollo de instituciones en favor de los pobres, y se pueden aprender lecciones desde la experiencia comparativa de las microfinanzas en los casos bolivianos e indonesio. En suma, a la luz de los cambios que han ocurrido en los mercados globales de capital y en las prioridades políticas, los requerimientos políticos para escapar de las crisis económicas han cambiado de manera significativa en los últimos diez años.

\section{Bibliografía}

[1] ALIAGA, IRINA y PAUL MOSLEY (2006): 'Microfinance under crisis conditions: the case of Bolivia' (Microfinazas bajo condiciones de crisis: el caso boliviano), capitulo 11 en T. Dichter y M. Harper (eds.) What's wrong with microfinance?, Rugby: Practical Impact Publishing.

[2] AGENOR, PIERRE-RICHARD (2005): 'The macroeconomics of poverty reduction', Manchester School, vol 73:4 (agosto), pp. 369-434.

[3] AUVINEN, JUHA AND NAFZIGER, WAYNE, (2002): Hunger, War and Displacement, Oxford: Oxford University Press.

[4] BOLIVIA (2006): Programa de gobierno MAS-IPSP: Bolivia digna, soberana y productiva para vivir bien. La Paz: Oficina del Presidente de la Republica.

[5] CARRASCO, SCARLETT ESCALANTE, y ERNESTO YANEZ (2005): 'Exclusión social y polarización como generadoras de conflicto: un análisis empírico para el caso de Bolivia', Revista de Estudios Economicos y Sociales (INE, La Paz) vol. 4 (September) pp. 7-55. 
[6] CARTER, MICHAEL y JULIAN MAY (1999): 'Poverty, livelihood and class in South Africa', World Development, vol. 27, pp. 1-20.

[7] CARTER, MICHAEL y CHRISTOPHER BARRETT (2006): 'The economics of poverty traps and persistent poverty: an asset-based approach' Journal of Development Studies, vol. 42 (febrero), pp. 178-199.

[8] COLLIER, PAUL y ANKE HOEFFLER (1996): 'On economic causes of civil war', Oxford Economic Papers, vol. 50, pp. 563-573.

[9] COLLIER, PAUL y ANKE HOEFFLER (2004): 'Greed and grievance in civil war', Oxford Economic Papers, vol. 56, pp. 563-595.

[10] DE FRANCO, MARIO y RICARDO GODOY (1990): The economic consequences of cocaine production in Bolivia: historical, local and macroeconomic perspectives. Harvard Institute for International Development, Cambridge, Mass.:unpublished paper.

[11] DOMINGO, PILAR (2009): 'Morales, the MAS and a revolution in the making', Chapter 6 in J. Grugel(ed) Governance after neoliberalism in Latin America, Oxford: Macmillan.

[12] DUASA, JARITA y PAUL MOSLEY (2006): 'Capital controls reconsidered: the case for 'smart' controls', The World Economy, volume ?, pp. 1203-1227.

[13] FIELDING, DAVID (2003): 'The economics of conflict', inaugural lecture, University of Leicester.

[14] FOWERAKER, JOE, TODD LANDMAN y NEIL HARVEY (2003): Governing Latin America. Bristol: Polity Press.

[15] GARCÍA, ÁLVARO, RAUL PRADA y LUIS TAPIA (2004): Memorias de octubre, La Paz: Muela del Diablo Editores.

[16] GOODHAND, JONATHAN (2003): paper on chronic poverty and conflict, World Development, March.

[17] GRAY-MOLINA, GEORGE, WILSON JIMENEZ, ERNESTO PEREZ DE RADA y ERNESTO YANEZ (1999): 'Pobreza y activos en Bolivia: que papel desempeña el capital social?' El Trimestre Economico, vol.66, pp. 365-417.

[18] GRUGEL, JEAN y PIA RIGGIROZZI (2006): Neodesarrollismo in Argentina: the construction of a post-crisis political economy, papel no editado, University of Sheffield.

[19] GRUGEL, JEAN y PIA RIGGIROZZI (2009): Governance after neoliberalism in Latin America, London: Palgrave Macmillan.

[20] HULME, DAVID y PAUL MOSLEY, Finance against Poverty, London: Routledge, 2 vols. 1996.

[21] INSTITUTO NACIONAL DE ESTADÍSTICA (INE) (2002): Pobreza y desigualdad en municipios de Bolivia: estimación del gasto de consumo combinando el Censo 2001 y las encuestas de hogares. La Paz: INE/UDAPE.

[22] INE (2004): Anuario Estadístico 2004, La Paz: Instituto Nacional de Estadística.

[23] LANDA, FERNANDO (2003): Pobreza y distribución del ingreso en Bolivia entre 1999 y 2002, unpublished paper, La Paz: UDAPE.

[24] LANDA, FERNANDO y WILSON JIMÉNEZ (2005): Bolivia: crecimiento 'pro-pobre' entre los años 1989 y 2002, Análisis económico (UDAPE, La Paz), vol. 20 (June), pp. 28-60.

[25] LAZARTE ROJAS, JORGE (2005): Entre los espectros del pasado y las incertidumbres del futuro: política y democracia en Bolivia a principios del siglo XXI (La Paz; Plural Editores). 
[26] LENTON, PAMELA y PAUL MOSLEY (2005): 'Incentivised trust', unpublished paper, University of Sheffield.

[27] LLOBET, CAYETANO (1999): Opas seremos? La Paz: Plural.

[28] LLOBET, CAYETANO (2005): SobreMesa, La Paz: El Observador.

[29] MARCONI, REYNALDO y PAUL MOSLEY (2006): 'Bolivia during the global crisis (1998-2004): towards a "macroeconomics of microfinance" Journal of International Development, vol. 18 , pp. 237-261.

[30] MESA, JOSE DE, TERESA GISBERT y CARLOS D. MESA GISBERT (2003): Historia de Bolivia, quinta edicion. La Paz: Editorial Gisbert.

[31] MOLINA, FERNANDO (2005): 'Causas de la inestabilidad económica de Bolivia', Pulso, 299 (27 May-2 June), p. 6.

[32] MORRISSON, CHRISTIAN, JEAN-DOMINIQUE LAFAY y SEBASTIEN DESSUS (1993): La Faisabilite politique de l'ajustement dans les pays africains, (La factibilidad política del ajuste en los países africanos), Document technique no 88, OECD Development Centre, Paris.

[33] MOSLEY, PAUL (2001): 'Microfinance and poverty in Bolivia', Journal of Development Studies, April 2001, pp. 101-132.

[34] MOSLEY, PAUL (2004a): 'Growth and severe poverty: a macro-micro approach'. Manchester: Chronic Poverty Research Centre.

[35] MOSLEY, PAUL (2004b): 'Institutions and politics in a Lewis-type growth model', Manchester School, December.

[36] MOSLEY, PAUL y SULEIMAN ABRAR (2005): 'Trust, conditionality and aid-effectiveness', unpublished paper presented at Cape Town Conference, May, to be published by World Bank.

[37] MOSLEY, PAUL, SULEIMAN ABRAR y BLESSING CHIRIPANHURA (2006): 'Escape routes from the rural poverty trap: evidence for three African countries', unpublished paper, University of Sheffield, March.

[38] MOSLEY, PAUL (2006): The dynamics of interpersonal and political trust: a case study of Bolivia, unpublished report to ESRC on grant RES-000-22-1168, University of Sheffield.

[39] MOSLEY, PAUL (2009): con Blessing Chiripanhura, Norbert Fiess, Jean Grugel, Ben Thirkell-White, The Politics of Poverty Reduction, informe para ESRC (Reino Unido: Economic and Social Research Council).

[40] NEWMAN, JOHN, MENNO PRADHAN y STEEN JORGENSON (1990?): 'Did workers gain from Bolivia's Emergency Social Fund?' World Bank Economic Review.

[41] NURKSE, RAGNAR (1953): Problems of capital formation in underdeveloped countries, London: Allen and Unwin.

[42] PAINTER, JAMES (1994): Bolivia and coca: a study in dependency, Boulder, Colorado: Lynne Rienner Publishers.

[43] PALDAM, MARTIN (1993): 'The socio-political reactions to balance of payments adjustments in LDCs: a study of nine cases from Latin America', papel no editado, Universidad de Aarhus, Dinamarca.

[44] PATTEN, RICHARD, J. ROSENGARD y D. JOHNSTON (2001): 'Microfinance success amidst macroeconomic failure: the experience of Bank Rakyat Indonesia during the east Asian crisis'. World Development, vol. 29, pp. 1057-1069. 
[45] RHYNE, ELISABETH (2001): Mainstreaming microfinance: how lending to the poor began, grew and came of age in Bolivia, West Hartford, CT, EE.UU: Kumarian Press.

[46] SIMMONS, BETH y ZACHARY ELKINS (2004): 'The globalisation of liberalisation: policy diffusion in the international political economy', American Political Science Review, vol. 98 (February 2004), pp. 171-189.

[47] SIVAK, MARTIN (2001): El dictador elegido: biografía no autorizada de Hugo Banzer, La Paz: Plural Editores.

[48] SUAREZ, HUGO JOSE (2003): Una semana fundamental: 10-18 octubre 2003, La Paz: Muela del Diablo Editores.

[49] VAN COTT, DONNA LEE (2003): 'From exclusion to inclusion: Bolivia's 2002 elections', Journal of Latin American Studies, vol. 35, pp. 751-775.

[50] WORLD BANK (2000): World development report 2000: Attacking poverty, Washington DC: World Bank.

[51] WORLD BANK (2005): Bolivia poverty assessment: establishing the basis for pro-poor growth, Report 28068-BO, Washington D.C. 
